\title{
Maternal metabolic stress may affect oviduct gatekeeper function
}

\author{
L Jordaens ${ }^{1}$, V Van Hoeck ${ }^{1}$, V Maillo², A Gutierrez-Adan², W F A Marei ${ }^{1,3}$, B Vlaeminck ${ }^{4}$, \\ S Thys ${ }^{5}$, R G Sturmey ${ }^{6}$, P E J Bols ${ }^{1}$ and J L M R Leroy ${ }^{1}$ \\ ${ }^{1}$ Laboratory for Veterinary Physiology and Biochemistry, Gamete Research Center, University of Antwerp, Wilrijk, \\ Belgium, ${ }^{2}$ INIA, Instituto Nacional de Investigacion y Tecnologia Agraria y Alimentaria, Madrid, Spain, ${ }^{3}$ Department \\ of Theriogenology, Faculty of Veterinary Medicine, Cairo University, Giza, Egypt, ${ }^{4}$ Laboratory for Animal Nutrition \\ and Animal Product Quality, Ghent University, Ghent, Belgium, ${ }^{5}$ Laboratory for Cell Biology and Histology, Core \\ Facility for Biomedical Microscopic Imaging, University of Antwerp, Antwerp, Belgium and ${ }^{6}$ Hull York Medical \\ School, Center for Cardiovascular and Metabolic Research, University of Hull, Hull, UK
}

Correspondence should be addressed to L Jordaens; Email: lies.jordaens@uantwerpen.be

\begin{abstract}
We hypothesized that elevated non-esterified fatty acids (NEFA) modify in vitro bovine oviduct epithelial cell (BOEC) metabolism and barrier function. Hereto, BOECs were studied in a polarized system with 24-h treatments at Day 9: (1) control $(0 \mu \mathrm{M} N E F A+0 \%$ EtOH), (2) solvent control ( $0 \mu \mathrm{M}$ NEFA + 0.45\% EtOH), (3) basal NEFA ( $720 \mu \mathrm{M} \mathrm{NEFA+0.45 \%} \mathrm{EtOH} \mathrm{in} \mathrm{the} \mathrm{basal} \mathrm{compartment)} \mathrm{and}$ (4) apical NEFA ( $720 \mu \mathrm{M}$ NEFA $+0.45 \%$ EtOH in the apical compartment). FITC-albumin was used for monolayer permeability assessment and related to transepithelial electric resistance (TER). Fatty acid (FA), glucose, lactate and pyruvate concentrations were measured in spent medium. Intracellular lipid droplets (LD) and FA uptake were studied using Bodipy 493/503 and immunolabelling of FA transporters (FAT/CD36, FABP3 and CAV1). BOEC-mRNA was retrieved for qRT-PCR. Results revealed that apical NEFA reduced relative TER increase $\mathbf{( 4 6 . 8 5 \% )}$ ) during treatment and increased FITC-albumin flux $(\mathbf{2 7 . 5 9} \%)$ compared to other treatments. In basal NEFA, FAs were transferred to the apical compartment as free FAs: mostly palmitic and oleic acid increased respectively $\mathbf{5 6 . 0}$ and $33.5 \%$ of initial FA concentrations. Apical NEFA allowed no FA transfer, but induced LD accumulation and upregulated FA transporter expression ( $\uparrow C D 36, \uparrow F A B P 3$ and $\uparrow C A V 1)$. Gene expression in apical NEFA indicated increased anti-apoptotic ( $\uparrow B C L 2)$ and anti-oxidative ( $\uparrow S O D 1)$ capacity, upregulated lipid metabolism ( $\uparrow C P T 1, \uparrow A C S L 1$ and $\downarrow A C A C A)$ and FA uptake ( $\uparrow C A V 1)$. All treatments had similar carbohydrate metabolism and oviduct function-specific gene expression (OVGP1, ESR1 and FOXJ1). Overall, elevated NEFAs affected BOEC metabolism and barrier function differently depending on NEFA exposure side. Data substantiate the concept of the oviduct as a gatekeeper that may actively alter early embryonic developmental conditions. Reproduction (2017) 153 759-773
\end{abstract}

\section{Introduction}

In dairy cattle, extensive genetic selection to promote milk yield has led to a drastic increase in energetic demands and reduced fertility (Leroy et al. 2008a,b). To support increased milk production, dairy cow metabolism shifts to prioritize lactation, causing metabolic stress, which can be manifested through increased lipolysis and elevated serum concentrations of non-esterified fatty acids (NEFAs) (Leroy et al. 2005). Similar observations have been described in women in whom metabolic stress, associated with e.g. obesity and type II diabetes, is linked with lipolytic disorders (Lash \& Armstrong 2009).

Elevated serum NEFAs are reflected in the ovarian follicular fluid (Leroy et al. 2004, Leroy et al. 2005,
Robker et al. 2009) and are recognized as important factors affecting fertility. As such, NEFAs have direct detrimental effects on murine folliculogenesis (Valckx et al. 2014), bovine oocyte nuclear maturation and developmental capacity (Jorritsma et al. 2004, Leroy et al. 2005, Aardema et al. 2011, Van Hoeck et al. 2011) and the quality of the resulting embryo (Van Hoeck et al. 2011). In women and mice, oocyte quality has also been related to metabolic alterations in follicular fluid (Valckx et al. 2012, 2015) with potentially lasting adverse effects in the offspring (Jungheim et al. 2011).

In addition, it has been demonstrated that elevated NEFAs can affect in vitro bovine oviduct epithelial cell (BOEC) physiology (Jordaens et al. 2015). Elevated NEFAs hampered BOEC physiology by reducing cell proliferation, cell migration capacity, cell functionality 
and monolayer integrity, in a cell polarity-dependent manner. However, insights in the pathways associated to these observations and in cellular responses arising from NEFA exposure are currently lacking. Furthermore, it's important to learn 'how', 'whether' and 'to which extent' intracellular fatty acid (FA) uptake and transepithelial transfer of these FAs can occur. Recent in vivo experiments indeed indicated that the conditions in the reproductive tract define its ability to sustain early embryo development (Rizos et al. 2010, Maillo et al. 2012, Matoba et al. 2012). As such, the oviductal environment in metabolically stressed lactating dairy cattle was less supportive for blastocyst formation compared to heifers (Rizos et al. 2010) and to non-lactating cows (Maillo et al. 2012). In vitro reports suggest this may be due to direct environmental effects of elevated NEFAs, as NEFA exposure during bovine embryo culture jeopardized embryo quality through reduced blastocyst formation and cell number, with a concomitant rise in apoptosis (Van Hoeck et al. 2013) and internalization of FAs (Listenberger et al. 2003, Leroy et al. 2010). In mice, similar observations have been made as exposure of murine embryos to pathological NEFA concentrations during in vitro culture, induced effects on embryo metabolism and growth (Jungheim et al. 2011). However, whether or not elevated serum NEFAs can be transferred across the oviduct epithelial lining and are actually reflected in the oviductal lumen, where they may contribute to suboptimal embryo growth conditions, remains to be elucidated.

It is furthermore unknown whether elevated NEFA concentrations may influence oviduct-specific characteristics such as permeability. Earlier Roche and coworkers (Roche et al. 2001) reported that FAs altered in vitro Caco-2 monolayer confluency by affecting transepithelial electric resistance (TER) and expression of tight junctions. In oviductal cells, a reduced TER and cell migration capacity were observed in the presence of elevated NEFAs (Jordaens et al. 2015), but mechanistic insights are currently lacking. Affecting oviduct epithelial permeability and thereby altering the oviduct gatekeeper function would reflect in the overall composition of the oviduct microenvironment as different molecules may be filtered from the serum to the oviductal lumen (Leese et al. 2007). NEFAs may therefore also indirectly affect early embryo development.

Studies expanding on the consequences of elevated NEFAs on oviduct cell function and micro-environment are scarce. Possibly, as in vivo studies remain challenging to perform due to specialist equipment and techniques and difficult to interpret considering the complexity of the whole organism (Velazquez et al. 2010). Hereto, an in vitro-polarized cell culture (PCC) system with hanging inserts (Miessen et al. 2011, Tahir et al. 2011) may provide a valid alternative as it promotes the preservation of both morphology and biology of native oviduct epithelium (Fotheringham et al. 2011) while focusing on immediate cellular responses of oviduct epithelial cells exclusively. It is therefore considered as a valuable tool to acquire primary mechanistic insights in the direct effects of NEFAs on BOEC physiology. In particular, BOEC metabolism and barrier function, oviduct-specific functions such as oviduct specific glycoprotein secretion, anti-oxidative and anti-apoptotic characteristics and cellular FA transfer or uptake are of interest, as they may influence early embryo development.

Therefore, in the present study, we hypothesized that elevated NEFA concentrations can affect BOEC physiology by altering BOEC metabolism and barrier function. Hereto, we aimed to obtain a more profound understanding in the direct effects of elevated NEFAs on BOEC physiology and gatekeeper features in a PCC by observing (1) BOEC monolayer integrity and permeability, (2) FA transfer across the monolayers, (3) intracellular lipid accumulation, (4) BOEC FA transporters, (5) BOEC energy metabolism and (6) mRNA expression of genes related to BOEC viability, oxidative stress, BOEC-specific functions and both carbohydrate and lipid metabolism. This research may ultimately further elucidate the direct effects of NEFAs on the oviductal micro-environment, affecting pre-implantation embryo development. This may contribute to the complex pathogenesis of infertility associated with lipolytic metabolic disorders.

\section{Materials and methods}

All chemicals were purchased from Thermo Fisher Scientific, unless stated otherwise.

\section{Primary BOEC culture: isolation and culture in a polarized cell culture (PCC) system}

BOECs were isolated and cultured as described previously (Jordaens et al. 2015). Briefly, in each replicate, 4 bovine oviducts from cows in the early luteal phase (days 3-5 of the estrous cycle) and ipsilateral to the ovulation site were obtained from a local slaughterhouse. As the pre-implantation embryo interacts with both ampulla and isthmus, BOECs from whole oviducts were mechanically isolated within $3 \mathrm{~h}$ after slaughter. BOEC number and viability were determined, using trypan blue exclusion and a hemocytometer and seeded at a density of $1 \times 10^{6} \mathrm{cells} / \mathrm{mL}$ in a polarized cell culture (PCC) system with hanging inserts (Corning, Snapwell, 6-well). Each compartment contained $2 \mathrm{~mL}$ culture medium, based on DMEM/F12 (containing 0.75\% w/v BSA (essentially FA free; Sigma-Aldrich), $5 \%$ v/v serum $(2.5 \%$ v/v Fetal Bovine serum, Greiner Bio-One, Frickenhausen, Germany; and $2.5 \%$ v/v Newborn Calf Serum, Sigma-Aldrich, St-Louis, MO, USA), 2.5\% v/v penicillin/streptomycin and $2 \% \mathrm{v} / \mathrm{v}$ amphotericin B) and was renewed initially after $24 \mathrm{~h}$, subsequently every $48 \mathrm{~h}$. 


\section{Preparation of the treatments}

The types and concentrations of free FAs used are based on the in vivo concentrations found in the serum of high-yielding dairy cows in negative energy balance (NEB) (Leroy et al. 2005). To mimic the FA profile during NEB, NEFA concentrations of $720 \mu \mathrm{M}$ (i.e. $230 \mu \mathrm{M}$ palmitic acid $(\mathrm{PA})+280 \mu \mathrm{M}$ stearic acid $(\mathrm{SA})+210 \mu \mathrm{M}$ oleic acid $(\mathrm{OA}))$ were implemented as a pathological condition and prepared as described by Van Hoeck and coworkers (Van Hoeck et al. 2011). Solubility of lipophilic NEFAs into hydrophilic culture was spectrophotometrically confirmed prior to use.

\section{Experimental design}

BOECs were maintained in hanging inserts and supported by medium replenishments of both compartments every $48 \mathrm{~h}$ until they reached confluency, as confirmed by transepithelial electrical resistance (TER) using an Avometer (Millicell-ERS, Millipore). Monolayer formation was defined confluent when the TER recordings exceeded $700 \Omega \mathrm{cm}^{2}$ (Chen et al. 2015) at Day 9. Ultimately at Day 9, pre-exposure medium samples were collected after which 4 treatments were established: (1) control: $0 \mu \mathrm{M}$ NEFA in both compartments, (2) solvent control: $0 \mu \mathrm{M} \mathrm{NEFA}+0.45 \% \mathrm{v} / \mathrm{v} \mathrm{EtOH}$ in both compartments, (3) basal NEFA: $720 \mu \mathrm{M}$ NEFA $+0.45 \% \mathrm{v} / \mathrm{v} \mathrm{EtOH}$ in the basal compartment and (4) apical NEFA: $720 \mu \mathrm{M}$ NEFA $+0.45 \% \mathrm{v} / \mathrm{v}$ $\mathrm{EtOH}$ in the apical compartment. Preparations of NEFA were added to the monolayers at Day 9 for $24 \mathrm{~h}$ as depicted in Fig. 1. After $24 \mathrm{~h}$ (Day 10), outcome parameters were assessed, spent medium from both compartments in all wells was sampled and BOECs were either collected using EDTA-trypsin for mRNA extraction or fixed in $4 \%$ paraformaldehyde for immunofluorescent staining. Per outcome parameter, samples from a total of 16 animals were used and analyzed as four pools of four.

\section{Outcome parameters}

\section{BOEC integrity and monolayer permeability}

TER measurements were recorded, both before (Day 9) and after NEFA exposure (Day 10) to observe monolayer confluence and integrity. Hereto, a Millicell-ERS (Millipore) was used according to the manufacturer's instructions. Monolayers were considered confluent when TER values ranged between 700 and $1100 \Omega \mathrm{cm}^{2}$ (Chen et al. 2015). Data were expressed as relative TER increase over the 24 -h treatment period. At Day 10 and immediately after NEFA exposure, monolayer permeability was determined by measuring macromolecular transport of $66 \mathrm{kDa}$ FITC-labeled albumin across the monolayers, as described by Chang and coworkers (Chang et al. 2000) in endothelial cells with some modifications to suit our design, objective and cell type. Briefly, in 4 repeats ( 2 inserts per flux direction within each treatment group and per replicate, total number of inserts $n=54)$, FITC-albumin $(15 \mu \mathrm{M})$ was dissolved in HBSS without phenol red and added to either the apical or the basal chamber (each 2 wells per treatment per replicate) to observe albumin flux in either direction. Unseeded inserts were used as a positive control to exclude effects due to the membrane properties. After $3 \mathrm{~h}$, medium in each compartment was mixed by pipetting and $20 \mu \mathrm{L}$ samples were submitted for FITC measurement at $490 \mathrm{~nm}$ excitation/530 nm emission using a Tecan microplate reader, Infinite 200 Pro (Tecan Trading AG, Switzerland). Both the supplemented and the nonsupplemented compartments were sampled to retrospectively

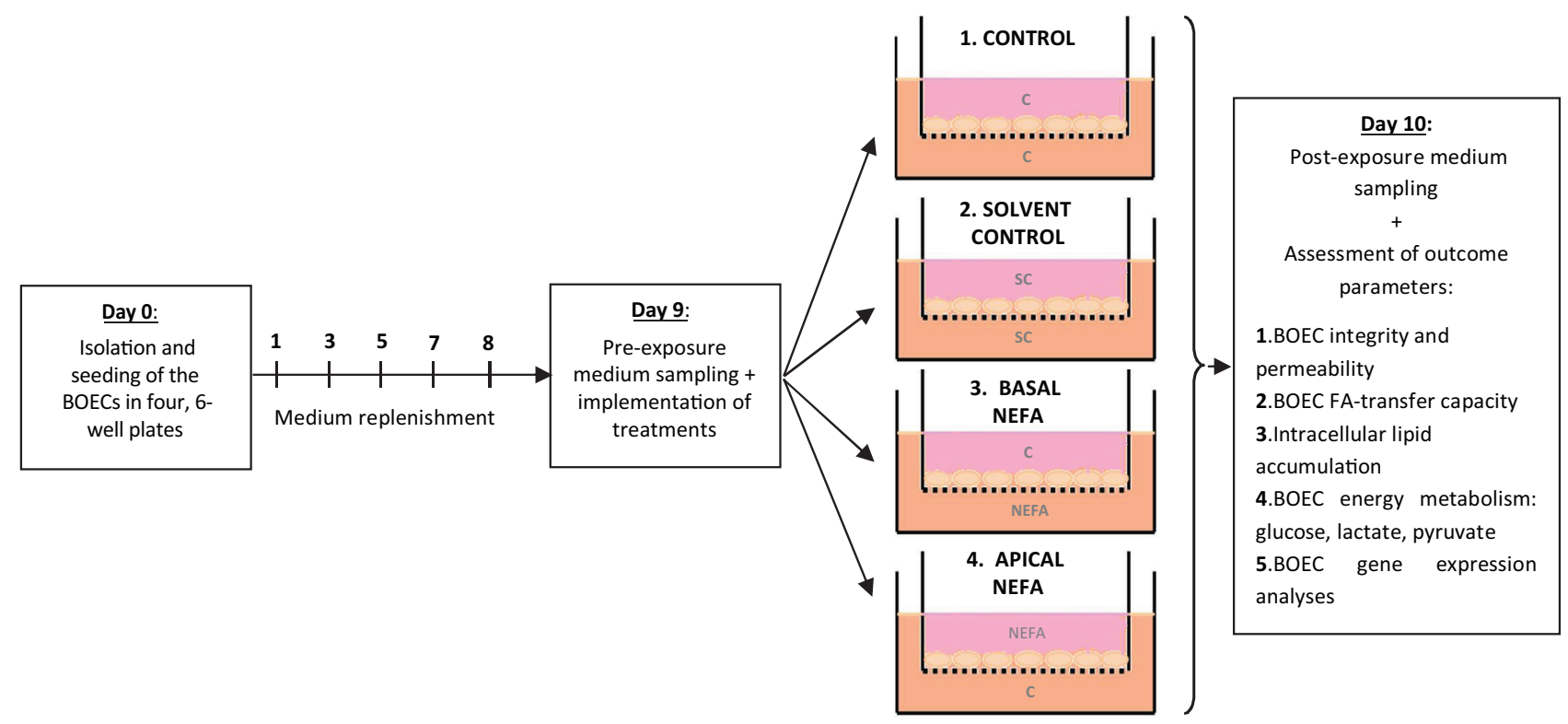

Figure 1 Experimental design to study the effects of NEFAs in a polarized cell culture system according to different exposure directions: $\mathrm{C}$, control medium containing $0 \mu \mathrm{M} \mathrm{NEFA}$; SC, solvent control medium containing $0 \mu \mathrm{M} \mathrm{NEFA}+0.45 \%$ EtOH; NEFA, $720 \mu \mathrm{M}$ NEFA with $230 \mu \mathrm{M}$ $\mathrm{PA}+280 \mu \mathrm{M} \mathrm{SA}+210 \mu \mathrm{M}$ OA. At Days 9 (pre-exposure samples) and 10 (post-exposure samples), spent media were collected. At Day 10 , other outcome parameters in BOECs were assessed. 
correlate the decrease in fluorescence from the supplemented compartment to the increase in fluorescence in the nonsupplemented compartment. Standard curves ranged from 0 to $2 \mu \mathrm{M}$, however, to match the FITC-albumin concentrations in the supplemented compartment, a $10 \times$ dilution was required. $R^{2}$ values of $>0.99$ and $\mathrm{CV}<10 \%$ were considered valid.

\section{BOEC fatty acid transfer capacity}

Spent medium from both NEFA-supplemented and their opposite compartments were spectrophotometrically analyzed for total FA concentrations, gas chromatographically for individual FA concentrations and for FA profiles per FA fraction (free or esterified) in 4 repeats.

Total FA concentrations: Total FA concentrations were measured at the 'Algemeen Medisch Labo' (AML, Antwerp, Belgium), using commercial photometric assays, RX Daytona (Randox Laboratories) in 4 replicates with 3 observations per treatment. Measurements were carried out according to manufacturer's instructions. The intra- and inter-assay coefficients of variation for all analyses were $<5 \%$.

FA profiles per FA fraction (free or esterified): FAs in spent medium (in 4 replicates using a pool of 2 inserts per treatment) were extracted as described by Löfgren and coworkers (Löfgren et al. 2012), with heneicosanoic acid (5 $\mu \mathrm{g})$ and triheptadecanoin $(5 \mu \mathrm{g})$ as internal standards. The FA extract was divided in three aliquots for the determination of (i) total FAs, (ii) FAs in triacylglycerols, cholesteryl esters and glycerophospholipids (esterified) and (iii) non-esterified fatty acids (free).

Total FAs were methylated by a consecutive basecatalyzed and an acid-catalyzed step (Vlaeminck et al. 2014). Esterified FAs (in triacylglycerols, cholesteryl esters and glycerophospholipids) were methylated using only the base-catalyzed step. For separation of the free FAs, the NEFA-containing hexane layer was methylated using an acidcatalyzed step. Fatty acid methyl esters were subsequently extracted with hexane.

Composition analysis of FA-methyl esters was carried out by gas chromatography (HP7890A, Agilent Technologies) with a split-splitless injector and flame ionization detector using a SP-2560 column $(75 \mathrm{~m} \times 0.18 \mathrm{~mm}$, i.d. $\times 0.14 \mu \mathrm{m}$ thickness, Supelco Analytical, Bellefonte, USA). The carrier gas was hydrogen (flow rate: $1 \mathrm{~mL} / \mathrm{min})$ with splitless injection $\left(t^{\circ}: 50^{\circ} \mathrm{C}\right.$ for $2.5 \mathrm{~min}, 175^{\circ} \mathrm{C}$ for $13 \mathrm{~min}$ and $215^{\circ} \mathrm{C}$ for $25 \mathrm{~min}$ ). Inlet and detector temperatures were 250 and $255^{\circ} \mathrm{C}$ respectively. Peaks were identified based on retention time comparisons with a mixture of FAME standards (GLC463, Nu-CheckPrep., Inc., Elysian, MN, USA). Quantification of FA-methyl esters was based on the area of the internal standard and on the conversion of peak areas to the weight of FAs by a theoretical response factor for each FA (Ackman \& Sipos 1964, Wolff et al. 1995).

\section{Intracellular lipid accumulation}

In three replicates, monolayers from 3 inserts per treatment were fixed at Day 10 of culture (and after NEFA exposure according to Fig. 1) in $4 \%$ phosphate buffered paraformaldehyde for $10 \mathrm{~min}$. BOECs were washed twice with
DPBS and permeabilized with saponin $(0.1 \% \mathrm{w} / \mathrm{v})$ (Carl Roth GmbH\&Co, Karlsruhe, Germany). Nuclei were stained with $5 \mu \mathrm{g} / \mathrm{mL}$ DAPI (Molecular Probes) for $5 \mathrm{~min}$ and subsequently washed with DPBS. Neutral lipids were stained with BODIPY 493/503 (Molecular Probes) $(20 \mu \mathrm{g} / \mathrm{mL})$ in DPBS for $1 \mathrm{~h}$, according to a modified protocol of Van Hoeck and coworkers (Van Hoeck et al. 2013). After staining the insert membranes and monolayers were removed from the insert housing and mounted on a microscope slides with Citifluor (VWR, Haasrode, Belgium). High-resolution images were obtained using Nikon Eclipse Ti-E inverted microscope, attached to a microlens-enhanced dual-spinning disk confocal system (UltraVIEW VoX; PerkinElmer) equipped with 405 and $488 \mathrm{~nm}$ diode lasers for the excitation of blue and green fluorophores respectively. For each monolayer, 10 random z-stack of $20 \mu \mathrm{m}$ with each $1 \mu \mathrm{m}$ intervals were made starting at the level of the insert membrane. In extended focus images, neutral lipid accumulation was compared qualitatively among treatments.

\section{BOEC fatty acid transporters}

At Day 10 of culture (and after NEFA exposure according to Fig. 1), 1 BOEC monolayer per treatment was fixed in $4 \%$ phosphate buffered paraformaldehyde for $10 \mathrm{~min}$ in 3 replicates. Monolayers were submitted to immunofluorescent staining, using polyclonal anti-FABP3 rabbit anti-bovine antibodies (MyBiosource), polyclonal anti-CD36 rabbit anti-bovine antibodies (Thermo Fisher Scientific) or polyclonal anti-CAV1 rabbit anti-bovine antibodies (Cell Signaling Technology). FITC-conjugated goat anti-rabbit IgG (Thermo Fisher Scientific) was used as secondary antibody according to manufacturer's instructions. Protocols were tested for non-specific primary and secondary antibody binding, and bis benzimide (Hoechst no 33342; Sigma-Aldrich) was used as nuclear stain. After staining, the insert membranes and monolayers were removed from the insert housing and mounted on a microscope slides with Citifluor (VWR). High-resolution images were obtained using Nikon Eclipse Ti-E inverted microscope (vide supra '3. Intracellular lipid accumulation'). For each monolayer, full thickness z-stacks with $0.5 \mu \mathrm{m}$ intervals were randomly made to localize the BOEC FA transporter expression. To quantify the BOEC FA transporter expression, 10 random single z-plane images per monolayer were made. Laser settings for the $405 \mathrm{~nm}$ laser line were used to focus all nuclei in each plane, whereas $488 \mathrm{~nm}$ laser settings were fixed for each transporter type. In each image, total green fluorescence and number of nuclei were measured using Volocity imaging software, version 6.3.1 (PerkinElmer). The level of FA transporter expression is presented as the mean amount of green fluorescent pixels counted per nucleus.

\section{BOEC energy metabolism: glucose, lactate and pyruvate concentrations}

Medium sampling was performed pairwise as repeated measures at Days 9 and 10: pre-exposure medium (routine BOEC, DMEM/F12-based culture medium) was added at Day 8 and sampled at Day 9 after 24-h incubation (4 replicates 
with 3 observations per treatment). Post-exposure medium, containing the different treatments, was subsequently added at Day 9 and sampled $24 \mathrm{~h}$ later at Day 10 . Both pre- and postexposure media were prepared from the same batch to assure all composing nutrients were identical. Immediately after collection, all medium samples were centrifuged at $1250 \mathrm{~g}$ ( $5 \mathrm{~min}$, room temperature) to avoid cellular contamination and possible confounding of the results by ongoing cellular activities in the medium. Subsequently, samples were snap frozen at $-196^{\circ} \mathrm{C}$ in liquid nitrogen and stored at $-80^{\circ} \mathrm{C}$ until further analysis. All analyses were performed within 3 months after sample collection. Lactate production and glucose and pyruvate consumption ( $n=96: 4$ replicates, 4 treatments, 3 wells per treatment with both an apical and a basolateral compartment) were determined by an ultrafluorometric assay of spent medium as described by Gardner and Leese (1990), with modifications by Guerif and coworkers (Guerif et al. 2013) using a Tecan microplate reader, Infinite 200 Pro (Tecan Trading AG, Switzerland). Blank medium aliquots (with no cellular contact) were collected to calculate the consumption/production, and data were expressed as nmol/ well/h. As differences in consumption or production data in the pre-exposure samples can only be due to cell number, these values were used to normalize post-exposure data. Data were expressed as a relative increase over the 24-h exposure period.

\section{BOEC gene expression analyses}

Gene expression analyses were performed using two BOEC monolayers per treatment in 4 replicates. The extraction of total RNA from cells was carried out using TRIzol reagent according to manufacturer's instructions. The isolated RNA was suspended in $1 \mathrm{~mL}$ of isopropanol for at least $20 \mathrm{~min}$. Subsequently, the isopropanol was vaporized in a vacuum chamber, and the RNA pellet was washed in $70 \%$ ethanol. Subsequently, mRNA was selected using the Dynabeads mRNA DIRECT Micro Kit (Ambion, Thermo Fisher Scientific) according to manufacturer's instructions with minor modifications (Bermejo-Álvarez et al. 2008). To eliminate potential contamination with genomic DNA, all samples were incubated with DNase, at $37^{\circ} \mathrm{C}$ for $30 \mathrm{~min}$ and at $90^{\circ} \mathrm{C}$ for $5 \mathrm{~min}$ (RQ1 RNase-Free DNase, Promega). RNA concentration was quantified at a wavelength of $260 \mathrm{~nm}$, and purity was assessed by the 260/280 ratio (Eppendorf BioPhotometer, Eppendorf Iberica, Madrid, Spain). cDNA synthesis and qPCR analysis were performed as described earlier (Maillo et al. 2016) in accordance with MIQE guidelines (Bustin et al. 2009). Briefly, RT reaction was carried out following the manufacturer's instructions (Epicentre Technologies Corp., Madison, USA) using poly $(\mathrm{T})$ primers, random primers and MMLV highperformance reverse transcriptase enzyme in a total volume of $50 \mu \mathrm{L}$ to prime the RT reaction and to produce cDNA. Tubes were heated to $70^{\circ} \mathrm{C}$ for $5 \mathrm{~min}$ to denature the secondary RNA structure and then the RT mix was completed with the addition of 50 units of reverse transcriptase. Afterward, they were incubated at $25^{\circ} \mathrm{C}$ for $10 \mathrm{~min}$ to favor the annealing of random primers, followed by $37^{\circ} \mathrm{C} 60 \mathrm{~min}$ to allow the RT of $\mathrm{RNA}$, and finally $85^{\circ} \mathrm{C} 5 \mathrm{~min}$ to denature the enzyme.
Primers (Table 1) were designed using Primer-BLAST software (www.ncbi.nlm.nih.gov/tools/primersblast/) to span exon-exon boundaries when possible. All qPCR reactions were carried out in duplicate on the Rotor Gene 6000 Real Time Cycler TM (Corbett Research, Sydney, Australia) by adding $2 \mu \mathrm{L}$ aliquot of each sample to the PCR mix (GoTaq qPCR Master Mix, Promega) containing the specific primers selected to amplify the genes listed in Table 1 . Cycling conditions were $94^{\circ} \mathrm{C}$ for $3 \mathrm{~min}$ followed by 35 cycles of $94^{\circ} \mathrm{C}$ for $15 \mathrm{~s}, 56^{\circ} \mathrm{C}$ for $30 \mathrm{~s}, 72^{\circ} \mathrm{C}$ for 10 and $10 \mathrm{~s}$ of fluorescence acquisition. Fold-changes in the relative gene expression of the target were determined using the equation $2^{-\triangle \Delta C T}$ (Livak \& Schmittgen 2001) using H2AZ, ACTB and GAPD as endogenous controls.

\section{Statistical analysis}

Data are expressed as means \pm S.E.M. and were analyzed using IBM SPSS Statistics, version 23 for Windows. Gene expression data were analyzed using Sigma Stat (Jandel Scientific, San Rafael, CA, USA) software package. Mean differences in mRNA transcript abundance, spent medium carbohydrate metabolites, albumin flux data, TER data, FA transfer and FA transporter expression data among the experimental groups were compared with mixed-model ANOVA and post hoc Bonferroni tests including the fixed effect of treatment, the random effect of the repeat and their interaction (excluded when not significant). For normality and equality of variance reasons, pyruvate and lactate data were log transformed prior to statistical analyses. Differences with $P$ values $<0.05$ were considered statistically significant.

\section{Results \\ BOEC integrity and monolayer permeability}

The TER measurements were expressed as 'relative TER increase' by comparing pre- and post-NEFA exposure measurements, as none of the treatments reduced TER to the extent that monolayer integrity was compromised (i.e. $<700 \Omega \mathrm{cm}^{2}$ (Chen et al. 2015)). Elevated NEFAs induced a significantly lower TER increase regardless of the exposure direction (Fig. 2).

The maximum FITC-albumin concentration in the non-supplemented compartment of unseeded wells was $4.3 \mu \mathrm{M}$. This flux was irrespective of assay direction and was correlated to the maximum FITC-albumin decrease in the opposite albumin-supplemented compartment. The maximum flux (i.e. concentration of FITC-albumin in the non-supplemented compartment) observed in the unseeded wells was therefore maximum $28.67 \%$ of the initial FITC-albumin concentration in the supplemented compartments at the beginning of the assay (i.e. $15 \mu \mathrm{M}$ ). Regardless of the treatment, when basal to apical flux was observed in seeded wells, the maximum FITC-albumin concentration in the non-supplemented compartment of the control wells was $0.51 \mu \mathrm{M}$ (or $3.4 \%$ ). When apicalto-basal flux was observed, the maximum flux was $1.8 \%$ of the initial FITC-albumin at the beginning of the assay 
Table 1 List of primers used showing primer sequences, fragment sizes, and gene bank accession numbers. GAPDH, H2AFZ and ACTB were used as endogenous controls.

\begin{tabular}{|c|c|c|c|c|}
\hline Gene & Gene name & Primer sequence $\left(5^{\prime}-3^{\prime}\right)$ & Fragment size (bp) & Gene bank accession no. \\
\hline ACACA & Acetyl-CoA carboxylase alpha & $\begin{array}{l}\text { AAGCAATGGATGAACCTTCTTC } \\
\text { GATGCCCAAGTCAGAGAGC }\end{array}$ & 196 & FN185963.1 \\
\hline ACSL1 & $\begin{array}{l}\text { Acyl-CoA synthetase long-chain family } \\
\text { member } 1\end{array}$ & $\begin{array}{l}\text { TGACTGTTGCTGGAGACTGG } \\
\text { TGTGCTTCTTCCTGTCGATG }\end{array}$ & 250 & NM_001076085.1 \\
\hline$A C T B$ & Actin, beta & $\begin{array}{l}\text { GAGAAGCTCTGCTACGTCG } \\
\text { CCAGACAGCACCGTGTTGG }\end{array}$ & 264 & AF191490.1 \\
\hline$B A X$ & BCL2-associated X protein & $\begin{array}{l}\text { CTGGAGCAGGTGCCTCAGGA } \\
\text { ATCTCGAAGGAAGTCCAGCGTC }\end{array}$ & 300 & NM_001166486.1 \\
\hline$B C L 2$ & B-Cell CLL/lymphoma 2 & $\begin{array}{l}\text { GGAGCTGGTGGTTGACTTTC } \\
\text { CTAGGTGGTCATTCAGGTAAG }\end{array}$ & 517 & BC147863.1 \\
\hline CAV1 & Caveolin 1 & $\begin{array}{l}\text { TCAGCCGTGTCTATTCC } \\
\text { АTTTCTTTCTGCGTGTTG }\end{array}$ & 103 & NM_174004.3 \\
\hline CD36 & CD36 molecule, fatty acid translocase & $\begin{array}{l}\text { GCTCCTTAAGCCATTCTTGGAT } \\
\text { CACCAGTGTCAACGCACTTT }\end{array}$ & 151 & NM_001278621.1 \\
\hline CPT1B & Carnitine palmitoyltransferase 1B & $\begin{array}{l}\text { CTGCCСGССTGGGAAATGCTGT } \\
\text { САGTCTCTCСТCССCGGGСTGG }\end{array}$ & 332 & NM_001034349.2 \\
\hline ESR1 & Estrogen receptor 1 & $\begin{array}{l}\text { CCCGCCAAGGTTCTGAGAATCC } \\
\text { CAAGGCGTGCCACGTAGAACTG }\end{array}$ & 159 & NM_001001443.1 \\
\hline FABP3 & Fatty acid binding protein 3 & $\begin{array}{l}\text { TTGTGCGGGAGATGGTTGA } \\
\text { TGCCGAGTCCAGGAGTAGCC }\end{array}$ & 147 & NM_174313.2 \\
\hline FOXJ1 & Forkhead box J1 & $\begin{array}{l}\text { AGCAAGGCCACCAAGATCACC } \\
\text { CCGAGGCACCTTGATGAAGCAC }\end{array}$ & 145 & NM_001192076.1 \\
\hline GAPDH & Glyceraldehyde-3-phosphate dehydrogenase & $\begin{array}{l}\text { ACCCAGAAGACTGTGGATGG } \\
\text { ATGCCTGCTTCACСACCTTC }\end{array}$ & 247 & NM_001034034.2 \\
\hline GPX1 & Glutathione peroxidase 1 & $\begin{array}{l}\text { GCAACCAGTTTGGGCATCA } \\
\text { CTCGCACTTTTCGAAGAGCATA }\end{array}$ & 116 & NM_174076.3 \\
\hline G6PD & Glucose-6-phosphate dehydrogenase & $\begin{array}{l}\text { CGCTGGGACGGGGTGCCСТTCATC } \\
\text { CGCCAGGCСTCCСGСАGTTCATCA }\end{array}$ & 347 & NM_001244135.1 \\
\hline$H 2 A F Z$ & H2A histone family, member Z & $\begin{array}{l}\text { AGGACGACTAGCCATGGACGTGTG } \\
\text { CCACCACCAGCAATTGTAGCCTTG }\end{array}$ & 209 & NM_174809 \\
\hline$\angle D H A$ & Lactate dehydrogenase A & $\begin{array}{l}\text { TTCTTAAGGAAGAACATGTC } \\
\text { TTCACGTTACGCTGGACCAA }\end{array}$ & 310 & NM_174099.2 \\
\hline$L P L$ & Lipoprotein lipase & $\begin{array}{l}\text { ATTGCTCAGCATGGCTCGGAAG } \\
\text { TCCCAGGGCCATACACTGACTG }\end{array}$ & 309 & NM_001075120.1 \\
\hline OVGP1 & Oviductal glycoprotein 1 & $\begin{array}{l}\text { AAGAATGAGGCCCAGCTCAC } \\
\text { TGCCGAAGATTTGGGGTCTC }\end{array}$ & 219 & NM_001080216.1 \\
\hline SHC1 & $\begin{array}{l}\text { SHC (Src homology } 2 \text { domain containing) } \\
\text { transforming protein } 1\end{array}$ & $\begin{array}{l}\text { GTGAGGTCTGGGGAGAAGC } \\
\text { GGTTCGGACAAAGGATCACC }\end{array}$ & 334 & NM_001075305 \\
\hline SCL2A1 & $\begin{array}{l}\text { Solute carrier family } 2 \text { (facilitated glucose } \\
\text { transporter) member } 1 \text { (former GLUT1) }\end{array}$ & $\begin{array}{l}\text { CTGATCCTGGGTCGCTTCAT } \\
\text { ACGTACATGGGCACAAAACCA }\end{array}$ & 68 & NM_174602.2 \\
\hline SOD1 & Superoxide dismutase 1 , soluble & $\begin{array}{l}\text { ATCATTGGCCGCACGATGGTG } \\
\text { CCACAGGCCAAACGACTTCCAG }\end{array}$ & 107 & NM_174615 \\
\hline TJP1 & Tight junction protein 1 & $\begin{array}{l}\text { AATCATCCGACTCCTCGTCG } \\
\text { CCCAAACACAGCGCGTAAAA }\end{array}$ & 255 & XM_010817146.1 \\
\hline TP53 & Tumor protein P53 & $\begin{array}{l}\text { CTCAGTCCTCTGCCATACTA } \\
\text { GGATCCAGGATAAGGTGAGC }\end{array}$ & 364 & NM_174201.2 \\
\hline
\end{tabular}

as the maximum FITC-albumin concentration in the nonsupplemented compartment of the control wells was $0.27 \mu \mathrm{M}$. Only apical NEFA significantly increased the proportion of FITC transfer (3.8\%) across the membrane $(P<0.05$, Fig. 3$)$ compared to that in controls, and only in basal-to-apical assay direction. Overall, albumin flux from the basal to the apical compartment was approximately two times higher than that seen in the opposite direction. When the FITC transfer direction was inverted (to 'apical to basal'), no treatment effects could be observed $(P>0.05)$.

\section{BOEC NEFA transfer capacity}

\section{Total FA concentration}

In basal NEFA, a $19 \%$ (or $122.5 \pm 4.3 \mu \mathrm{M}$ ) reduction of total FA content in the supplemented compartment could be detected after 24-h exposure. In parallel, there was a $21 \%$ (or merely $12.7 \pm 1.4 \mu \mathrm{M}$ ) rise in FA content in the apical chamber compared to that in the initial concentrations. By contrast, in apical NEFA, total FA content fell by $53.4 \%(334.2 \pm 28.2 \mu \mathrm{M})$ with no FA transfer detected in the basal chamber. 


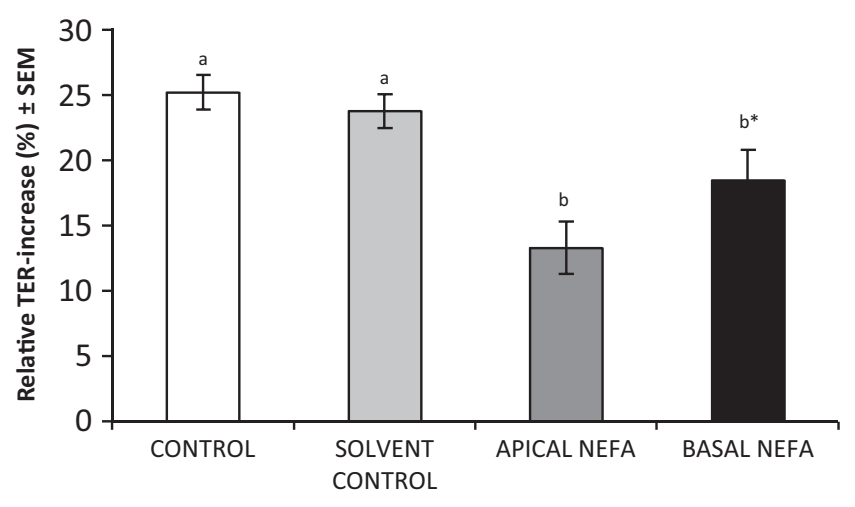

Figure 2 Relative TER increase was calculated through comparison of pre- and post-NEFA exposure TER measurements. ${ }^{a, b}$ Different superscripts per bar indicate the statistical significant differences $(P<0.05) ; * P=0.05$.

\section{FA profiling per FA fraction (free or esterified)}

To specify the transfer, the total FA concentrations were separated in individual FAs and classified as free or bound, esterified FAs (triglycerides, cholesterol esters and phospholipids). For both apical and basal NEFA, significant differences in total FA could only be found in the free FA fraction. In basal NEFA, the significantly increased FAs in the non-supplemented, apical compartment were C16:0 $(56.0 \pm 20.0 \%, P=0.042)$, C18:0 $(60.0 \pm 27.0 \%, P=0.098)$ and C18:1 $(33.5 \pm 6.0 \%$, $P=0.082)$ in the total FA-fraction, whereas in the free, unbound fraction, $\mathrm{C} 14: 0(58.0 \pm 27.8 \%, P=0.035)$, C16:1-cis-9 $\quad(81.1 \pm 19.3 \%, \quad P=0.002), \quad$ C18:1-cis-9 $(72.2 \pm 3.9 \%, P=0.017)$ and C18:1-cis-11 $(30.8 \pm 7.0 \%$, $P=0.004$ ) were found to be significantly increased.

In apical NEFA, no differences in FA increase could be detected in the non-supplemented compartment, as no FA transfer was observed $(P>0.05)$.

\section{Intracellular lipid accumulation}

Apical addition of NEFA caused an increased accumulation of neutral lipid droplets compared to other treatments (Fig. 4). Numerous lipid droplets were observed in the cytoplasm and distributed evenly across the BOEC monolayer. By contrast, when NEFA was added to the basal compartment, there was only limited lipid droplet accumulation in the BOECs. No lipid droplets were observed in the control groups.

\section{BOEC fatty acid transporters}

Fatty acid translocase/CD36 protein expression was upregulated in apical NEFA with 54.35 and 50.08\% compared to that in basal NEFA and control conditions respectively $(P<0.001)$. Both APICAL and BASAL NEFA showed similar FABP3 expression and were upregulated compared to CONTROLs by an average of $58.15 \%(P<0.001)$. CAV1 expression in apical NEFA
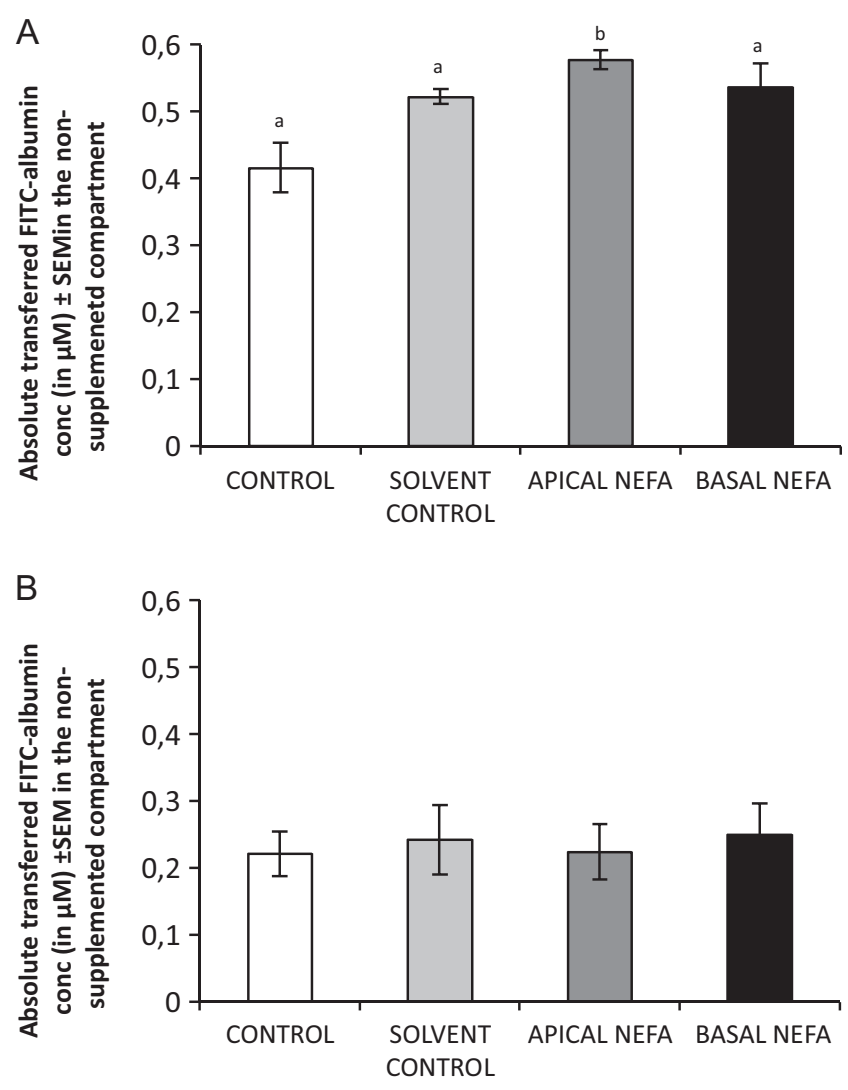

Figure 3 The permeability assay showed FITC-albumin flux measured in the non-supplemented compartment after a 3-h assay in which the FITC-albumin flux from the basal to the apical compartment (A) and the flux from the apical to the basal compartment (B) were observed. ${ }^{a, b}$ Different superscripts per bar indicate statistically significant differences $(P<0.05)$.

was increased with $46.69 \%(P<0.001)$ and $52.90 \%$ $(P<0.001)$ compared to that in basal NEFA and controls respectively (Fig. 5).

\section{BOEC energy metabolism: glucose, lactate and pyruvate concentrations}

Under untreated conditions, BOECs depleted $49.91 \pm 3.61 \mathrm{nmol} / \mathrm{well} / \mathrm{h}$ of glucose from the apical compartment and $55.54 \pm 10.82 \mathrm{nmol} / \mathrm{well} / \mathrm{h}$ from the basal compartment. In addition, $35.69 \pm 5.04 \mathrm{nmol} /$ well/h of pyruvate was depleted from the apical compartment and $38.87 \pm 7.16 \mathrm{nmol} / \mathrm{well} / \mathrm{h}$ from the basal compartment. BOECs released $141.21 \pm 8.31 \mathrm{nmol} /$ well/h of lactate into the apical chamber and $152.58 \pm 5.33 \mathrm{nmol} / \mathrm{well} / \mathrm{h}$ into the basal compartment.

Twenty four hours after the application of NEFA treatments, mean glucose release rose to $77.36 \pm 3.54 \mathrm{nmol} / \mathrm{well} / \mathrm{h}$ in the apical compartment and $139.26 \pm 35.81 \mathrm{nmol} / \mathrm{well} / \mathrm{h}$ in the basal chamber. Pyruvate depletion from the apical compartment was largely unchanged in response to NEFA addition $(34.76 \mathrm{nmol} / \mathrm{well} / \mathrm{h})$, although depletion from the 

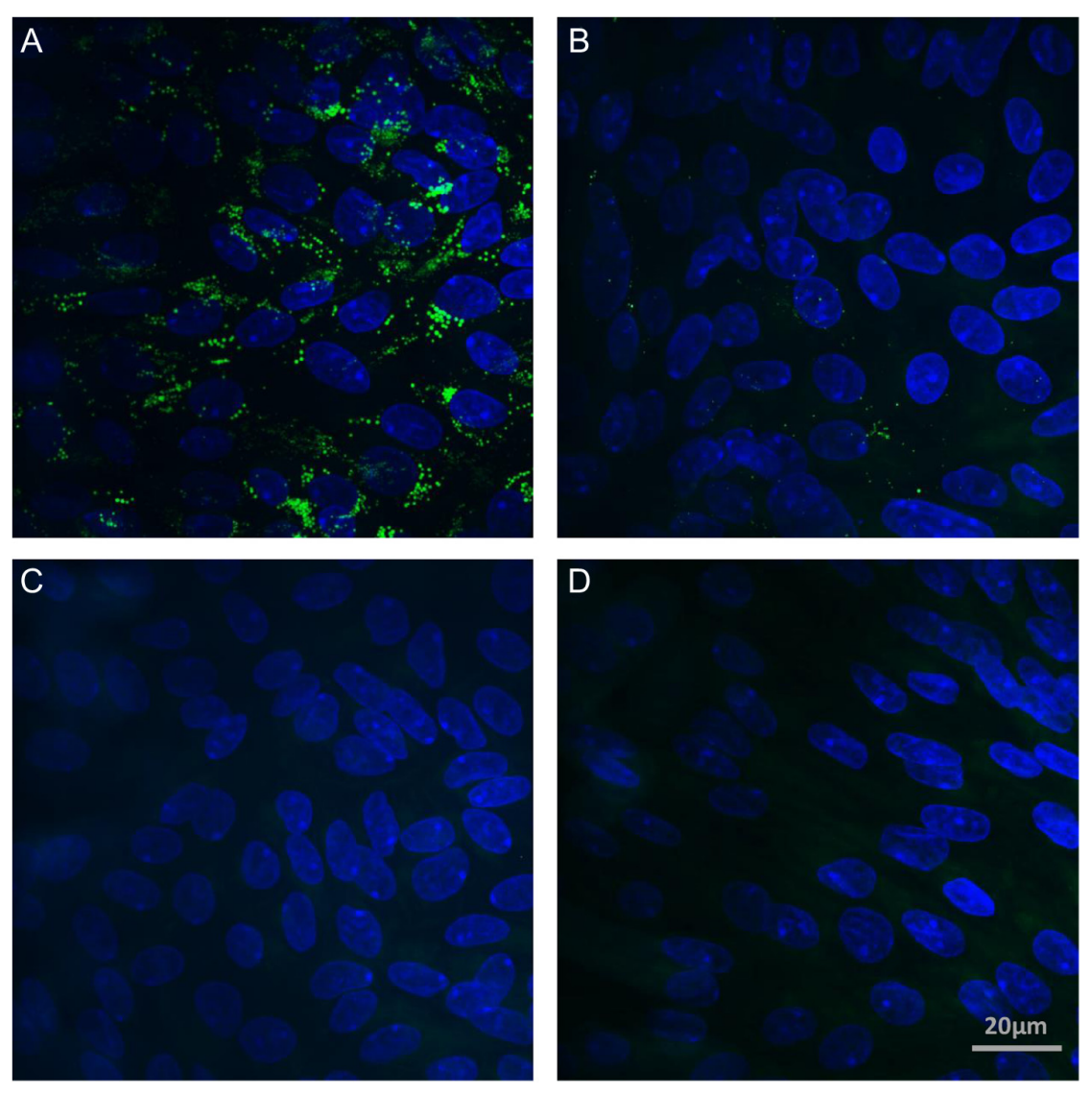

Figure 4 Lipid droplet analysis was performed using Bodipy 493/503 (green) to visualize intracytoplasmic droplets of neutral lipids and DAPI (blue) for staining nuclei. Monolayers from the control group $(\mathrm{C})$ and solvent control (D) showed no lipid droplets, whereas BOEC monolayers from the apical NEFA group (A) clearly showed the accumulation of lipids in the cells, and BASAL NEFA (B) displayed little-to-no lipid droplets. Images were made at $60 \times$ magnification using confocal microscopy.
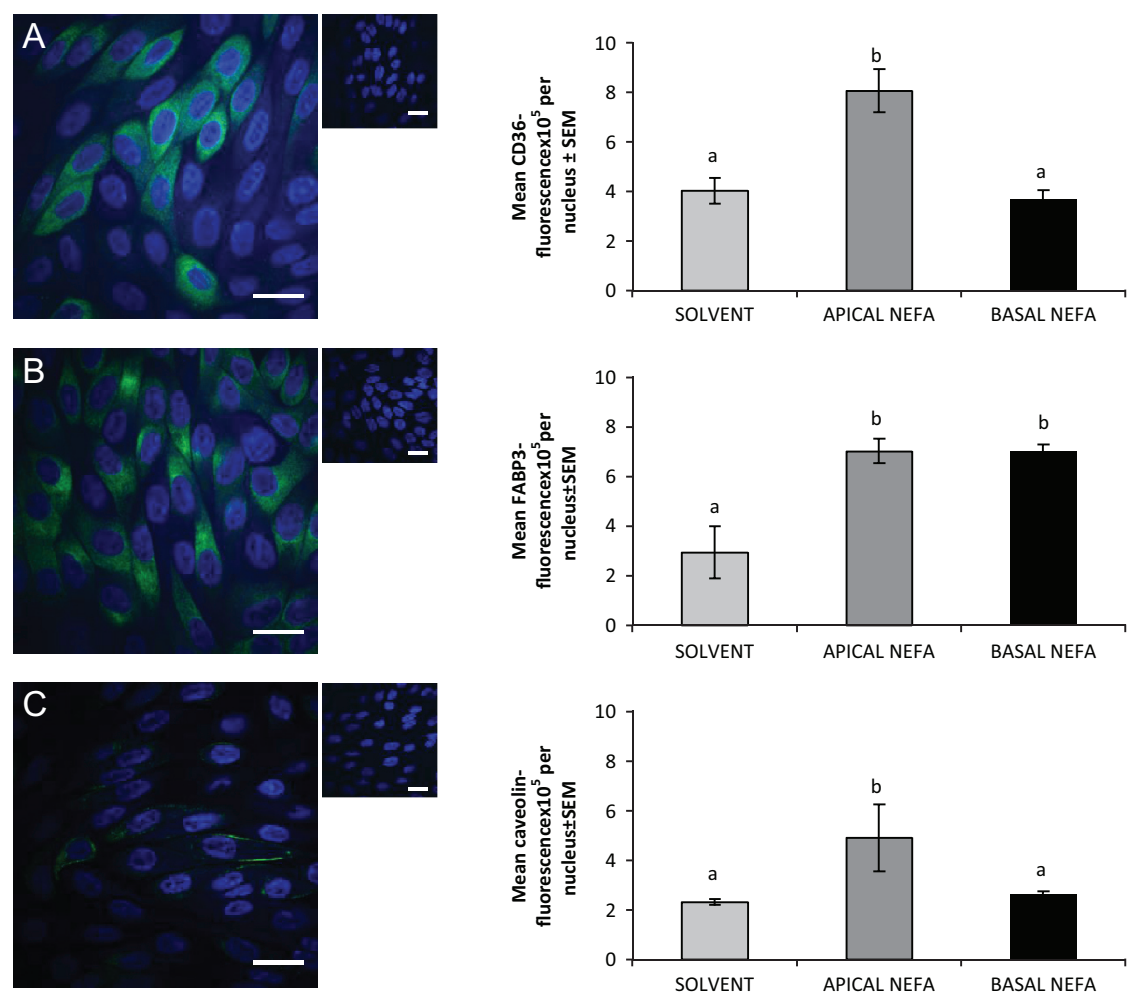

$\square$ SOLVENT

APICAL NEFA; BASAL NEFA

Figure 5 Immunolabelling of specific fatty acid transporters was performed to visualize and quantify specific FA transporter expression (green) per nucleus (blue). Fatty acid translocase CD36 (A), fatty acid-binding protein 3 (FABP3) (B) and caveolin 1 (CAV1) (C) are presented with their respective negative controls and mean transporter fluorescence per nucleus in different treatments. Scale bars indicate $20 \mu \mathrm{m}$. ${ }^{\mathrm{a}, \mathrm{b}}$ Different superscripts per bar indicate statistically significant differences $(P<0.05)$. 
basal compartment rose to $51.36 \pm 8.34 \mathrm{nmol} / \mathrm{well} / \mathrm{h}$. Lactate appearance in the apical compartment was $154.92 \pm 14.42 \mathrm{nmol} / \mathrm{well} / \mathrm{h}$ and in the basal compartment was $190.32 \pm 11.99 \mathrm{nmol} /$ well/h (Fig. 6).

No differences among the treatments could be detected.

\section{BOEC gene expression analysis}

The effects of BOEC NEFA exposure on the expression profile of genes involved in apoptosis (Fig. 7A), oxidative stress and specific BOEC function (Fig. 7B)related genes was subsequently investigated. Addition of NEFA to the apical compartment led to increased expression of $B C L 2$, compared to basal addition and control groups $(P<0.01)$, the consequence of which
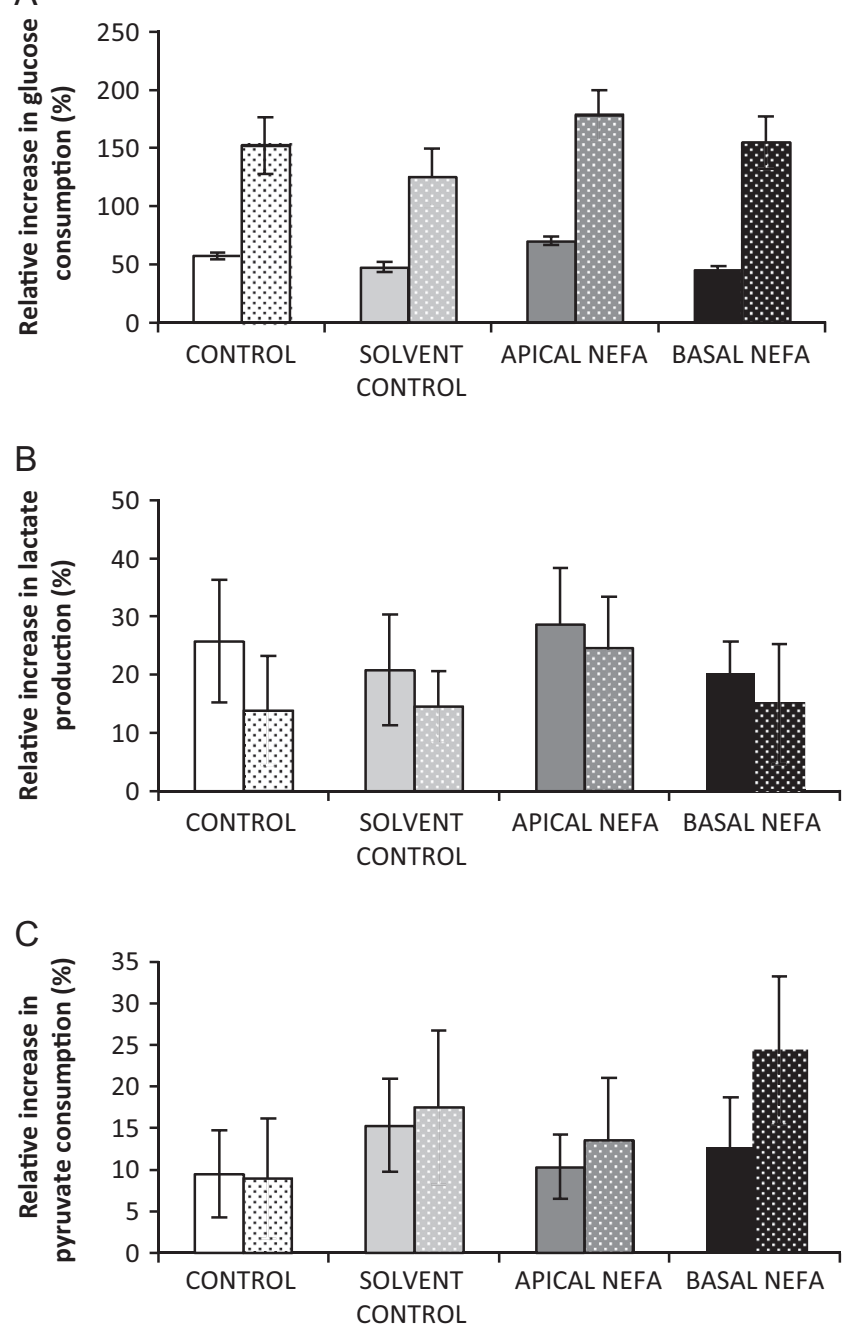

Figure 6 Glucose (A) and pyruvate (C) consumption and lactate (B) production $(\%)$ in spent medium were expressed as relative values of pre- and post-NEFA exposure samples taken with a 24-h interval and in different treatment groups. Full bars represent the apical compartment, and dotted bars represent the basal compartment. was to reduce the ratio of $B A X / B C L 2(P<0.01)$. Stress adaptor protein, $S H C 1$, was upregulated in response to apically administered NEFA $(P<0.05)$, although this was also apparent in the solvent control $(P<0.01)$. In addition, expression of SOD1 was upregulated in response to apical administration of NEFA $(P<0.05)$. Expression of OVGP1 (oviduct-specific glycoprotein expression), ESR1 (estrogen receptor expression) and FOXJ1 (ciliogenesis) were all unchanged in response to NEFA and regardless of the exposure direction. Next, the impact of NEFA exposure on genes related to energy metabolism (Fig. 7C and D) was examined. mRNA expression of G6PD was downregulated after addition of NEFA to the apical chamber $(P<0.05)$ but upregulated when NEFA was added to the basal compartment $(P<0.05)$. The expression of CPT1B $(P<0.05)$ and $A C S L 1(P<0.05)$ transcripts were upregulated, whereas ACACA expression $(P<0.05)$ was decreased in response to apical addition of NEFA. Expression of BOEC FA transporters resulted in upregulated CAV1 $(P<0.001)$ expression in APICAL NEFA compared to those in other treatments (Fig. 7E). Overall, fold-changes were low except for BCL2 and CAV1.

\section{Discussion}

In this study, we hypothesized that elevated serum NEFA concentrations alter BOEC physiology, and more specifically, BOEC metabolism and barrier function, potentially affecting the zygote's micro-environment. Hereto, PCC system with hanging inserts was used to approach the BOECs in a most physiologically relevant manner (Fotheringham et al. 2011).

Overall, data indicate that APICAL NEFA resulted in an increased FITC-albumin flux from the basal to the apical compartment. This increased monolayer permeability was also associated with reduced monolayer growth as suggested by slower increasing TER values from Days 9 to 10. In basal NEFA, NEFA concentrations decreased in the basal compartment with a concomitant increase in the apical chamber indicating limited FA transfer. While apical FA administration resulted in the increased lipid droplet formation and no transfer to the basal compartment. Depletion of carbohydrate metabolites seemed mostly active in the basal compartment, regardless of the treatments, substantiating the distinct effects of cellular polarity on the use of energy substrates in the culture system. Furthermore, apical NEFA induced anti-apoptotic and anti-oxidative pathways as suggested by increased expression of $B C L 2$ and SOD1 and may stimulate BOEC lipid metabolism through increased intracellular FA uptake ( $\uparrow C A V 1$ and $\uparrow F A$-transporter protein expression CD36, FABP3 and CAV1), and upregulation of CPT1B and ACSL1. To our knowledge, the present study is the first to attempt a deeper understanding in the characteristics of BOECs under the influence of elevated NEFAs, hereby confirming 

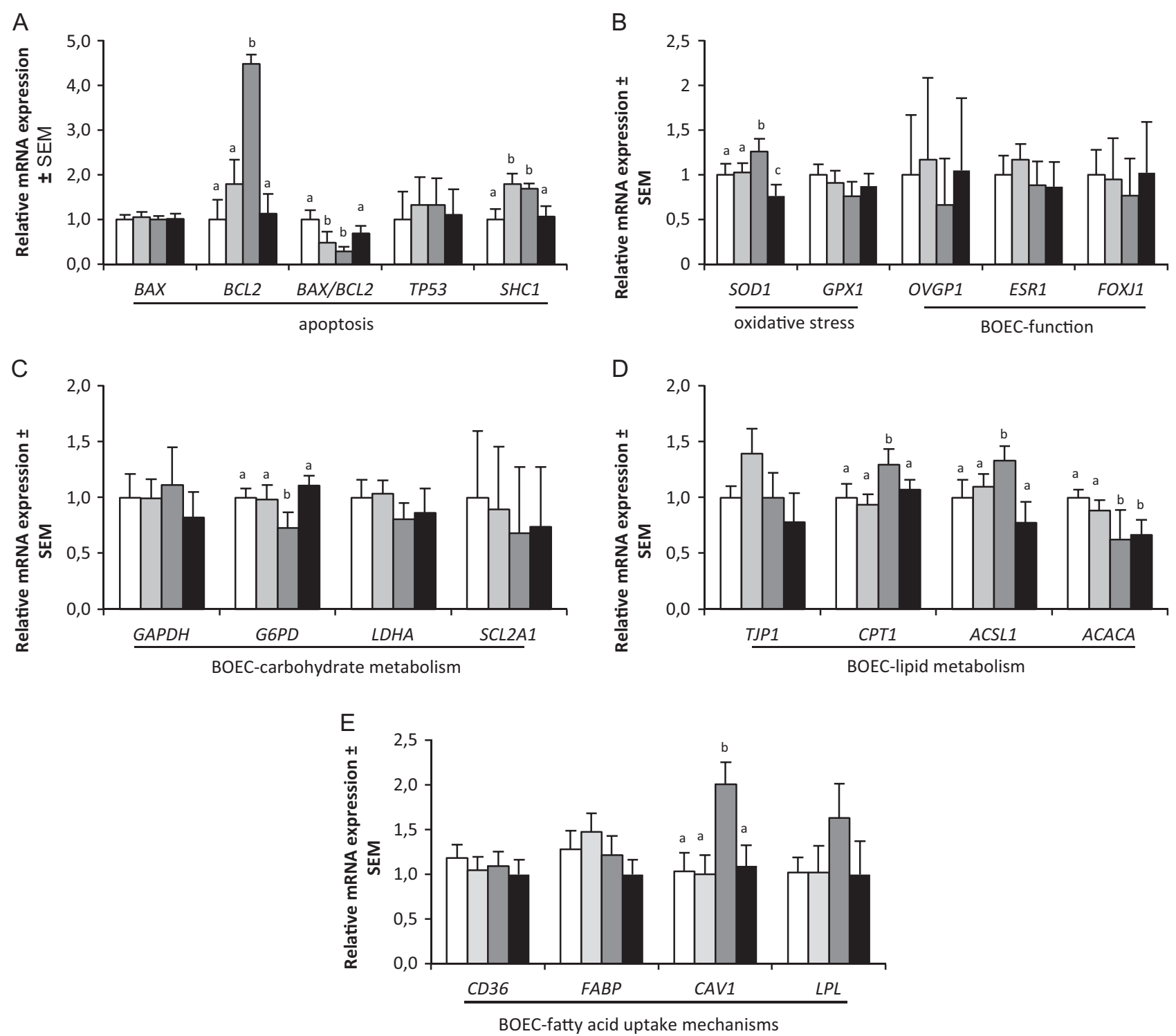

CONTROL; $\square$ SOLVENT CONTROL; $\square$ APICAL NEFA;

BASAL NEFA

Figure 7 mRNA transcript abundance ( \pm S.E.M.) after qRT-PCR gene expression analyses. Genes are sorted based on function: (A) apoptosis, (B) oxidative stress and BOEC function, (C) BOEC carbohydrate metabolism, (D) BOEC lipid metabolism and (E) FA uptake. ${ }^{a, b, c}$ Different superscripts per bar indicate statistically significant differences $(P<0.05)$.

cell polarity within the culture system and localizing different FA transporters.

Characterization of monolayer integrity by means of TER measurements resulted in ongoing increase in TER values during the NEFA exposure period due to continuous cell growth (Jordaens et al. 2015). In rat mammary epithelium, similar effects were observed and were considered to result from palmitic and stearic acid exposure (Wicha et al. 1979). Data furthermore indicated that apical NEFA resulted in reduced TER increase during the 24-h NEFA exposure period and therefore decreased the tightness of intercellular cell contact (Chen et al. 2015). These data were supported by the monolayer permeability assessment using FITClabeled albumin. Here, only apical NEFA resulted in an increased FITC-albumin flux suggesting increased monolayer permeability and reduced monolayer tight junction quality (Anderson \& Van Itallie 2009) in this treatment. Earlier, Roche and coworkers (Roche et al. 2001) made similar observations in Caco2-cells and reported that both TER permeability and expression of tight junctions decreased due to elevated FAs and the tight junction modulating capacity of NEFAs. Considering the apical positioning of tight junctions between adjacent cells, the increased monolayer permeability in apical NEFA of our study, may result from a more intense 
NEFA/tight junction contact in this treatment. The effects on permeability here observed, however, were limited specifically to the basal-to-apical albumin flux only. When the assay direction was inverted, total flux did not show any treatment effects. Apical-to-basal albumin flux was, however, lower compared to basal-to-apical flux, suggesting the oviductal lining to be still intact. It may also suggest intracellular uptake of the albumin in the apical-to-basal assay direction considering the equal amounts of albumin decrease in the supplemented compartments (Fig. 8) in both assay directions, which can be explained by the expression of albumin-binding cell surface receptors on the apical cell side of the oviduct only (Argaves \& Morales 2004).

These findings and unpublished fluorescence microscopic imaging may therefore question the accuracy of the apical-to-basal assay direction as permeability parameter, but do provide us with interesting considerations when assessing the FA transfer data.

FA transfer across the BOEC monolayers in basal NEFA showed a $19.5 \%$ FA decrease in the supplemented, basal compartment and a $21.1 \%$ increase in the opposite,
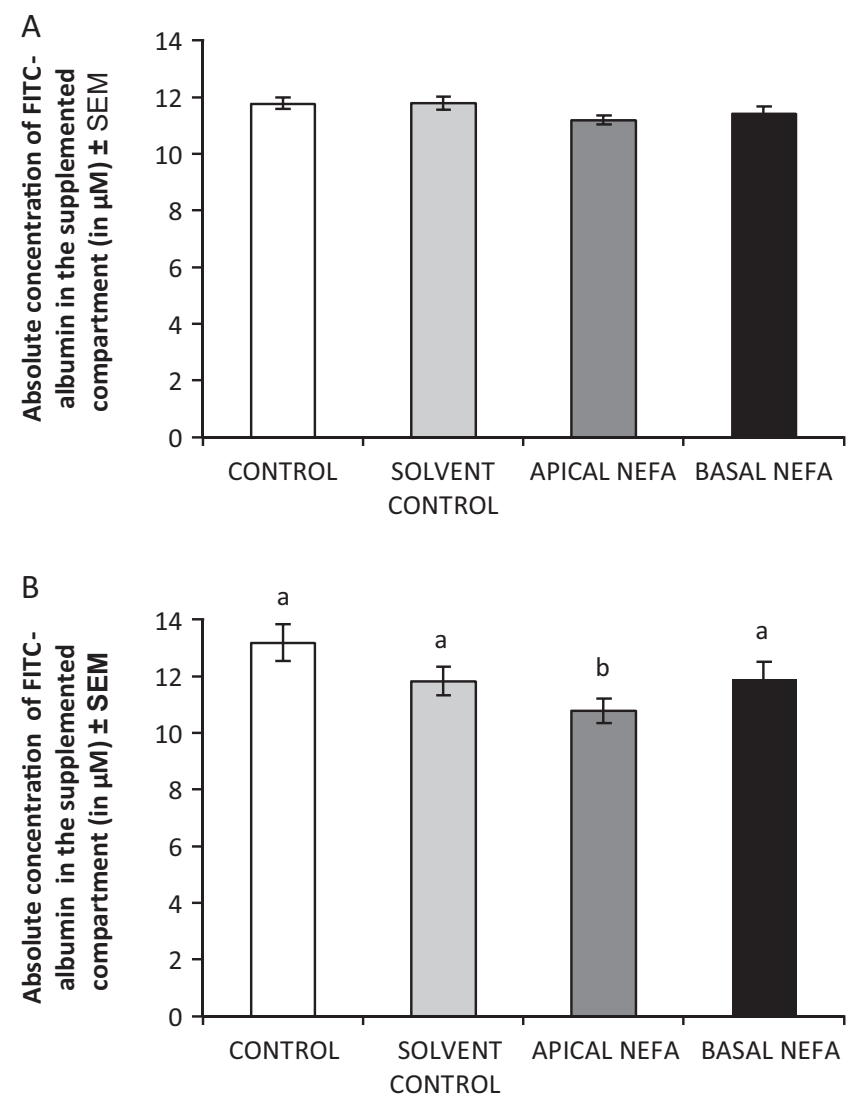

Figure 8 The permeability assay showed a decrease in FITC-albumin concentrations measured in the albumin-supplemented compartment after a 3-h assay in both the basal-to-apical (A) and apical-to-basal (B) assay direction. ${ }^{a, b}$ Different superscripts per bar indicate statistically significant differences $(P<0.05)$. apical compartment. The absolute values of the transfer, however, suggest that only a minor proportion of the FAs are transferred from the basal-to-the apical compartment and substantiate the concept of a potential gatekeeper function of the oviduct. Intervening with transfer of detrimental metabolites to the oviductal lumen may thus be considered as an embryoprotective mechanism. When observing the transferred FAs in closer detail, we determined that all transferred FAs were unbound FAs and that it was mostly oleic and palmitic acid that could be transferred to the apical compartment. These data indicate that FA transfer might be a selective process with a distinct active component for FA uptake (Glatz et al. 2010). Gas chromatographic analysis also revealed nonsupplemented FAs to be present in the luminal chamber, suggesting some degree of metabolic modification. For example, the presence of $\mathrm{C} 14: 0$, which was not added basally, may be indicative for de novo synthesis or conversion of C16:0 and C18:0 through partial oxidation (Lopaschuk et al. 2010). The presence C16:1-cis-9 may be a consequence of desaturation of PA and C18:1cis-11 from elongation (Jakobsson et al. 2006). Therefore, not only transfer but also FA metabolism could be detected in this treatment (Fig. 9 for conceptualization). In contrast to this, when NEFA was added to the apical chamber, there was no subsequent appearance in the basal compartment. The FA concentration in the apical supplemented compartment did, however, decrease by more than $50 \%$ over a 24 -h timespan. The reduced apical FA concentration, without signs of FA transfer, suggests intracellular FA uptake for storage in lipid droplets. Indeed, an increased accumulation of cytoplasmic lipid droplets in BOECs was observed in this treatment using Bodipy staining. The differences in lipid accumulation between the treatments were so apparent that no further quantification steps were undertaken. Cnop and coworkers (Cnop et al. 2001) observed lipid droplet formation in rat pancreatic cells and suggested cellular triglyceride accumulation as a cytoprotective mechanism against FA-induced lipotoxicity. In our current data, FA deposition in neutral lipid droplets was most abundantly observed in apical NEFA. Basal NEFA showed lipid droplets to a limited extent, whereas lipid accumulation was completely absent in the control and solvent control. On the basal cell side, FABPs require non-albumin-bound FAs for intracellular FA uptake, which requires lipoprotein lipases that are typically expressed by endothelium (Glatz et al. 2010). These lipases are not present in our experimental design and may elucidate the lack of lipid accumulation in BASAL NEFA as most supplemented NEFAs in our experiments are albumin bound. The apical cell side, on the other hand, and as mentioned previously, typically expresses caveolins, megalins, cubilins and lipoproteins allowing albumin-bound FA endocytosis (Moestrup \& Verroust 2001, Argaves \& Morales 2004), facilitating cellular uptake of NEFA/albumin complexes from the luminal 

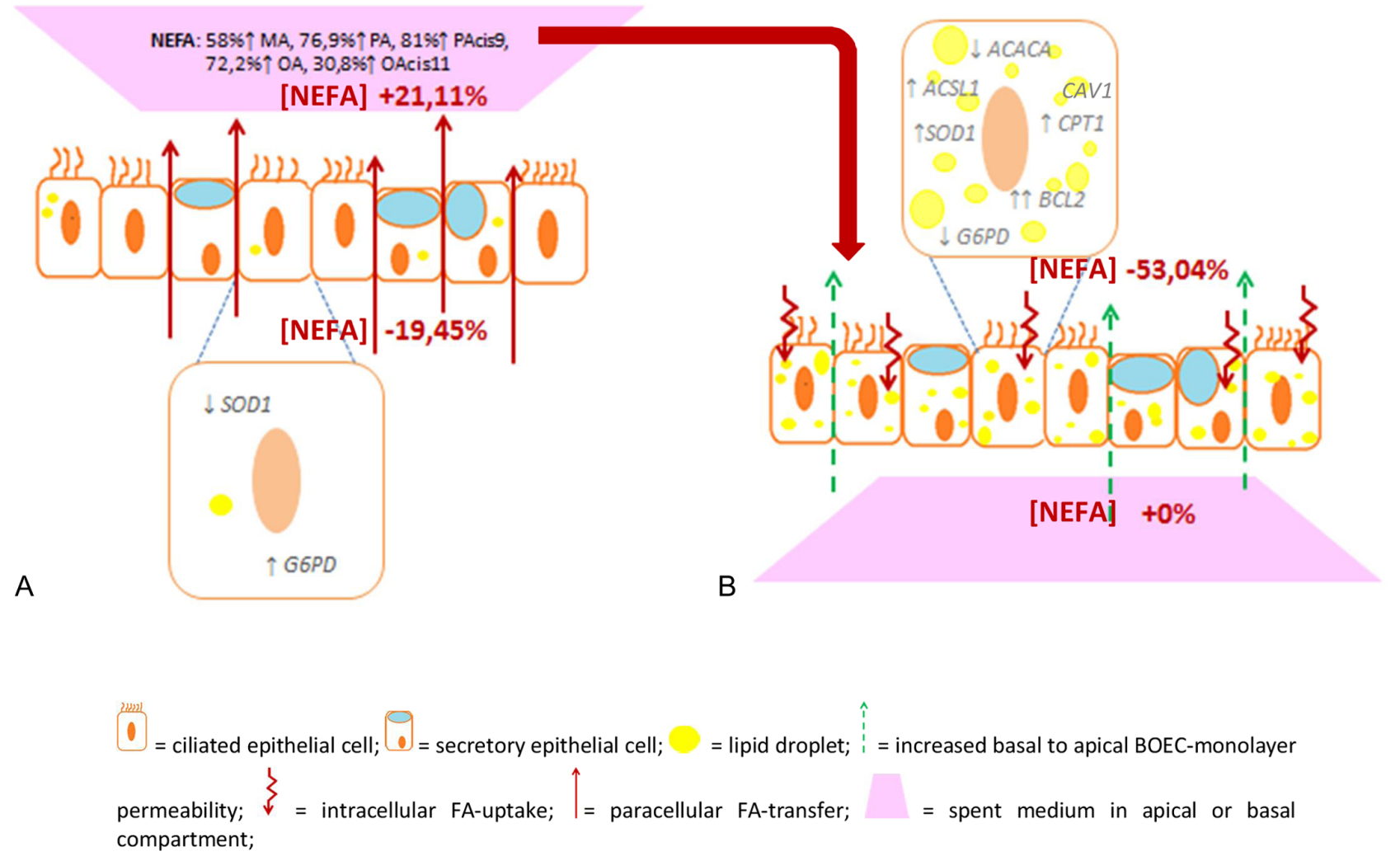

Figure 9 Graphic summary of the obtained results and conceptualization of fatty acid transfer across BOEC monolayers as suggested in the experiments previously. Red arrows indicate the FA transfer: via paracellular transport the basally supplemented FAs (A) are directed to the apical oviductal lumen compartment as non-esterified FAs, where they can be internalized by the cells and directly used as an energy substrate or in case of abundance, stored in lipid droplets (B). Gene expression is altered to allow the cells metabolic adaptation and upregulated anti-oxidative and anti-apoptotic pathways after exposure to elevated NEFAs. Green arrows suggest the increased permeability from the basal to the apical compartment in apical NEFA, proposing the possibility that the oviductal micro-environment may be subjected to all kinds of metabolic changes. Nuclei are orange, secretory granules are blue and lipid droplets are depicted in yellow. These data suggest cellular adaptation to changing environmental conditions.

chamber in our experimental setting. The presence (and abundance) of these transporters was confirmed in the current in vitro model through immunolabelling of BOEC FA transporters and may elucidate the quantitative difference in lipid droplets observed between treatments. In this respect, CAV1 mRNA transcript abundance was upregulated in apical NEFA compared to other treatments, which resulted in increased translation of CAV1. FAT/CD36 and FABP3 showed similar FA transporter expression in APICAL NEFA; however, no differences in mRNA transcripts could be detected when comparing different treatments. The latter might be explained by the increased use of the transcripts for translation with limited de novo transcriptional activity during the period investigated $(24 \mathrm{~h})$ as seen in early embryos (Robert 2010). Interestingly, CD36 transporters are typically expressed in tissues that favor high FA metabolism, as seen in mammary glands (Spitsberg et al. 1995), and also, metabolic conditions have shown to alter FA utilization and FA transporter expression as observed in adipocytes of diabetic rats (Berk et al. 1997) and as simulated in the current experimental setting.
The fact that yet a few lipid droplets could be detected in basal NEFA can be accounted to the limited FA transfer to the apical compartment in this treatment. Furthermore, these observations suit our findings made in the permeability assay where intracellular albumin uptake could only be observed when the fluorescent albumin was supplemented in the apical compartment. Complementary to these findings, basal NEFA treatment resulted in little-to-no differences in mRNA transcript abundance in the selected genes regarding lipid metabolism, possibly since the administered FAs are not taken up or partly redirected to the apical compartment. Gene expression analysis in apical NEFA, otherwise, resulted in increased lipid oxidation and reduced lipid synthesis. These data are suggestive for increased lipid metabolism of BOECs. However, and due to the abundance of the supplemented FAs, the supply may surpass the FA metabolism rate. Hereto, lipid storage may be employed as an adaptive tool to fulfill mitochondrial energy supply without hindering the redox status and by reducing the amount of lipotoxic intermediates (Aon et al. 2014). This mechanism not only 
protects the cells from NEFA's detrimental effects but also may 'purify' the oviductal microenvironment. The environmental conditions for optimal embryo growth can thus be significantly improved, which is crucial considering the critical changes the embryo undergoes during its stay in the oviduct (Latham \& Schultz 2001, Inbar-Feigenberg et al. 2013).

Analysis of spent medium for BOEC-carbohydrate metabolites did not reveal any significant differences in the consumption of glucose or pyruvate or production of lactate. In this respect, data are consistent with BOEC transcriptome data. Regarding the genes selected for the assessment of BOEC energy metabolism, only G6PD transcript abundance showed significant differences: G6PD was downregulated in apical NEFA and upregulated in basal NEFA; however, none of the other glucose metabolism-related genes were affected. This suggests that glucose may be increasingly directed toward the pentose phosphate pathway in basal NEFA, but the overall consumption was not affected. Regardless of the treatment, glucose uptake was most apparent in the basal, serum compartment, shifting glucose metabolites such as lactate in the apical compartment. In vivo BOECs are also provided with glucose via the serum (Leese 1988): our findings therefore support the natural conditions. Earlier experiments (Jordaens et al. 2015), however, indicated that during the 24-h exposure window, BOEC monolayers showed continuous growth. In the current study, similar effects have been observed in increasing TER values and elevated post-exposure glucose consumption in control groups. The latter was therefore normalized using pre-exposure data from the controls to minimize false interpretation. BOEC monolayers also showed an altered mitotic capacity, altered migration capacity and modified functionality due to elevated NEFAs (Jordaens et al. 2015), which may easily mask the turnover differences. In other cell types, similar NEFA effects have been observed. Rat hepatocytes showed increased apoptosis due to steatosis after OA and PA exposure (Ricchi et al. 2009), pancreatic B-cells in rats were hyperplastic with morphological abnormalities under the influence of FAs (Milburn et al. 1995) and mouse embryos lacked cell proliferation capacity and showed a reduced developmental competence (Nonogaki et al. 1994). Interpretation of the current glucose, pyruvate and lactate turnover data should therefore be done with caution as the NEFA conditions are known to affect monolayer characteristics. This is further supported by the data on gene expression as we observed increased expression of genes related to FA uptake, CAV1 in apical NEFA. Caveolins are membrane proteins, typically expressed at the apical cell side, involved in clathrin-independent endocytosis of proteins and lipids (Nabi \& Le 2003). Upregulation of these proteins in the presence of FA abundance may elucidate the increased intracellular lipid uptake. Furthermore, upregulation of lipid metabolism $\beta$-oxidation ( $\uparrow C P T 1$ and ACSL1) in this treatment, with the downregulation of FA synthesis-related genes $(\downarrow A C A C A)$ appears to confirm our theory on embryoprotective 'purification' of the oviduct microenvironment. The excess of FAs presented to the cells apically may therefore be consumed as a metabolic fuel, whereas de novo FA synthesis may be limited (Aon et al. 2014). In most tissues, de novo FA synthesis is of minor importance as the cellular requirements are predominantly met through FA supply via the blood. Increased levels of circulating FAs inhibit FA synthesis (Weis et al. 1986) and may result in decreased transcriptional activity of ACACA, as seen in the current data. The excessive FA oxidation may also prompt to increase oxidative stress (Aon et al. 2014) in BOECs. The upregulation of BCL2 and SOD1 in apical NEFA may therefore be a direct reaction of BOECs to NEFA exposure, increasing the cells' antioxidative and anti-apoptotic capacity. Harvey and coworkers (Harvey et al. 1995) and Tse and coworkers (Tse et al. 2008) made similar observations in embryo/ BOEC co-cultures and may further explain BOEC's embryoprotective capacity.

Ultimately, our findings may contribute to the concept that elevated NEFAs may modify the composition of the oviduct luminal fluid and alter the pre-implantation embryo's microenvironment. However, specific modifications were made to the experimental design. In this respect, NEFA exposure was limited to $24 \mathrm{~h}$, whereas in vivo NEFA concentrations are elevated over longer periods (Butler et al. 2003). Prolonged in vitro FA incubation was, however, in other cell types, associated with a significant decrease in cell viability (Ricchi et al. 2009). Furthermore, even acute NEFA exposure induced negative effects on BOECs and remains the only option to solely observe the direct cellular effects of NEFAs. In addition, the use of serum for optimal cell attachment compromised the definition of the culture conditions. To minimize the serum effects, concentrations were contained to $5 \%$, and the serum was analyzed for NEFA content prior to use. Further in vivo studies are required to investigate the changes in the oviduct luminal fluid associated with maternal metabolic disorders and how they may affect the micro-environment of the preimplantation embryo. Nonetheless, our in vitro findings provide novel insights into the understanding of oviduct interactions with FAs.

In conclusion, elevated NEFAs affect BOEC metabolism and barrier function in a polarity-dependent manner. In this respect, BOECs in basal NEFA potentially shield the luminal environment from elevated NEFAs by allowing only a limited amount of FAs to be transferred from the basal to the apical compartment. BOECs in APICAL NEFA may clear the micro-environment of the pre-implantation embryo from NEFAs through increased monolayer permeability, intracellular lipid accumulation and FA metabolism. Overall, the oviduct may modulate 
its micro-environment in favor of the early embryo by alleviating the potential lipotoxic effects.

\section{Declaration of interest}

The authors declare that there is no conflict of interest that could be perceived as prejudicing the impartiality of the research reported.

\section{Funding}

This research did not receive any specific grant from any funding agency in the public, commercial or not-for-profit sector.

\section{Acknowledgements}

The authors acknowledge Els Merckx and Silke Andries of the University of Antwerp Gamete Research Center, for their outstanding technical assistance throughout the experiments, and the AML 'Antwerps Medisch Labo' for the NEFA analyses.

\section{References}

Aardema H, Vos PLAM, Lolicato F, Roelen BA, Knijn HM, Vaandrager AB, Helms JB \& Gadella BM 2011 Oleic acid prevents detrimental effects of saturated fatty acids on bovine oocyte developmental competence. Biology of Reproduction 85 62-69. (doi:10.1095/ biolreprod.110.088815)

Ackman RG \& Sipos JC 1964 Application of specific response factors in the gas chromatographic analysis of methyl esters of fatty acids with flame ionization detectors. Journal of the American Oil Chemists' Society $4 \mathbf{1}$ 377-378. (doi:10.1007/bf02654818)

Anderson JM \& Van Itallie CM 2009 Physiology and function of the tight junction. Cold Spring Harbor Perspectives in Biology 1 a002584. (doi:10.1101/cshperspect.a000950)

Aon MA, Bhatt N \& Cortassa SC 2014 Mitochondrial and cellular mechanisms for managing lipid excess. Frontiers in Physiology 5282. (doi:10.3389/fphys.2014.00282)

Argaves WS \& Morales CR 2004 Immunolocalizationof cubilin, megalin, apolipoprotein J and apolipoprotein A-I in the uterus and oviduct. Molecular Reproduction and Development 69 419-427. (doi:10.1002/ mrd.20174)

Berk PD, Zhou SI, Kiang CL, Stump D, Bradbury M \& Isola LM 1997 Uptake of long chain free fatty acids is selectively upregulated in adipocytes of Zucker rats with genetic obesity and non-insulin-dependent diabetes mellitus. Journal of Biological Chemistry 272 8830-8835. (doi:10.1074/ jbc.272.13.8830)

Bermejo-Álvarez P, Rizo, D, Rath D, Lonergan P \& Gutierrez-Adan A 2008 Epigenetic differences between male and female bovine blastocysts produced in vitro. Physiological Genomics 32 264-272. (doi:10.1152/ physiolgenomics.00234.2007)

Bustin SA, Bene, V, Garson JA, Hellemans J, Higgett J, Kubista M, Mueller R, Nolan T, Pfaffl MW, Shipley GL et al. 2009 The MIQE guidelines: minimim Information for publication of quantative realtime PCR experiments. Clinical Chemistry 55 611-622. (doi:10.1373/ clinchem.2008.112797)

Butler ST, Marr AL, Pelton SH, Radcliff RP \& Lucy MC 2003 Insulin restores $\mathrm{GH}$ responsiveness during lactation induced negative energy balance in dairy cattle: effects of expression of IGF-I and GH receptor-1A. Journal of Endocrinology 176 205-217. (doi:10.1677/joe.0.1760205)

Chang YS, Munn LL, Hillsley MV, Dull RO, Yuan J, Lakshminarayanan S, Gardner TW, Jain RK \& Tarbell JM 2000 Effect of vascular endothelial growth factor on cultured endothelial cell monolayer transport properties Microvascular Research 59 265-277. (doi:10.1006/mvre.1999.2225)
Chen S, Einspanier R \& Schoen J 2015 Transepithelial electrical resistance (TEER): a functional parameter to monitor the quality of oviduct epithelial cells cultured on filter supports. Histochemistry and Cell Biology 144 509-515. (doi:10.1007/s00418-015-1351-1)

Cnop M, Hannaert JC, Hoorens A, Eizirik DL \& Pipeleers DG 2001 Inverse relationschip between cytotoxicity of free fatty acids in pancreatic islet cells and cellular triglyceride accumulation. Diabetes 50 1771-1777. (doi:10.2337/diabetes.50.8.1771)

Fotheringham S, Levanon K \& Drapkin R 2011 Ex vivo culture of human primary fallopian tube epithelial cells. Journal of Visualized Experiments 51 e2728. (doi:10.3791/2728)

Gardner DK \& Leese HJ 1990 Concentrations of nutrients in mouse oviduct fluid and their effects on embryo development and metabolism in vitro. Journal of Reproduction and Fertility 88 361-368. (doi:10.1530/ jrf.0.0880361)

Glatz JF, Luiken JJ \& Bonen A 2010 Membrane fatty acid transporters as regulators of lipid metabolism: implications for metabolic disease. Physiological Reviews 90 367-417. (doi:10.1152/physrev.00003.2009)

Guerif F, McKeegan P, Leese HJ \& Sturmey RG 2013 A simple approach for COnsumption and RElease (CORE) analysis of metabolic activity in single mammalian embryos. PLOS ONE 8 e67834. (doi:10.1371/journal. pone.0067834)

Harvey MB, Arcellana-Panlilio MY, Zhang X, Schultz GA \& Watson AJ 1995 Expression of genes encoding antioxidant enzymes in preimplantation mouse and cow embryos and primary bovine oviduct cultures employed for embryo coculture. Biology of Reproduction 53 532-540. (doi:10.1095/biolreprod53.3.532)

Inbar-Feigenberg M, Choufani S, Butcher DT, Roifman M \& Weksberg R 2013 Basic concepts of epigenetics. Fertility and Sterility 99 607-615. (doi:10.1016/j.fertnstert.2013.01.117)

Jakobsson A, Westerberg R \& Jacobsson A 2006 Fatty acid elongases in mammals: their regulation and roles in metabolism. Progress in Lipid Research 45 237-249. (doi:10.1016/j.plipres.2006.01.004)

Jordaens L, Arias-Alvarez M, Pintelon I, Thys S, Valckx S, Dezhkam Y, Bols PEJ \& Leroy JLMR 2015 Elevated non-esterified fatty acid concentrations hamper bovine oviductal epithelial cell physiology in three different in vitro culture systems. Theriogenology 84 899-910. (doi:10.1016/j. theriogenology.2015.05.030)

Jorritsma R, César ML, Hermans JT, Kruitwagen CLJJ, Vos PLAM \& Kruip TAM 2004 Effects of non-esterified fatty acids on bovine granulosa cells and developmental potential of oocytes in vitro. Animal Reproduction Science 81 225-235. (doi:10.1016/j.anireprosci.2003.10.005)

Jungheim ES, Louden ED, Chi MMY, Frolova AI, Riley JK \& Moley KH 2011 Preimplantation exposure of mouse embryos to palmitic acids results in fetal growth restriction followed by catch-up growth in the offspring. Biology of Reproduction 85 678-683. (doi:10.1095/ biolreprod.111.092148)

Lash MM \& Armstrong A 2009 Impact of obesity on women's health. Fertility and Sterility 91 1712-1716. (doi:10.1016/j.fertnstert.2008.02.141)

Latham KE \& Schultz RM 2001 Embryonic genome activation. Frontiers in Bioscience 6 748-759. (doi:10.2741/A639)

Leese HJ 1988 The formation and function of oviduct fluid. Journal of Reproduction and Fertility 82 843-856. (doi:10.1530/jrf.0.0820843)

Leese HJ, Hugentobler SA, Gray SM, Morris DG, Sturmey RG, Whitear SL \& Sreenan JM 2007 Female reproductive tract fluids: composition, mechanism of formation and potential role in the developmental origins of health and disease. Reproduction, Fertility and Development 20 1-8. (doi:10.1071/RD07153)

Leroy JLMR, Vanholder T, Delanghe JR, Opsomer G, Van Soom A \& Bols PEJ 2004 Metabolite and ionic composition of follicular fluid from different-sized follicles and their relationship to serum concentrations in dairy cows. Animal Reproduction Science 80 201-211. (doi:10.1016/ S0378-4320(03)00173-8)

Leroy JLMR, Vanholder T, Mateusen B, Christophe A, Opsomer G, de Kruif A, Genicot G \& Van Soom A 2005 Non-esterified fatty acids in follicular fluid of dairy cows and their effect on developmental capacity of bovine oocytes in vitro. Reproduction 130 485-495. (doi:10.1530/rep.1.00735)

Leroy JLMR, Opsomer G, Van Soom A, Goovaerts IG \& Bols PEJ 2008a Reduced fertility in high-yielding dairy cows: are the oocyte and embryo in danger? Part I. The importance of negative energy balance and altered corpus luteum function to the reduction of oocyte and embryo quality in high-yielding dairy cow. Reproduction in Domestic Animals 43 612-622. (doi:10.1111/j.1439-0531.2007.00960.x) 
Leroy JLMR, Van Soom A, Opsomer G, Goovaerts IG \& Bols PEJ $2008 \mathrm{~b}$ Reduced fertility in high-yielding dairy cows: are the oocyte and embryo in danger? Part II. Mechanisms linking nutrition and reduced oocyte and embryo quality in high-yielding dairy cows. Reproduction in Domestic Animals 43 623-632. (doi:10.1111/j.1439-0531.2007.00961.x)

Leroy JLMR, Van Hoeck V, Clemente M, Rizos D, Gutierrez-Adan A, Van Soom A, Uytterhoeven M \& Bols PEJ 2010 The effect of nutritionally induced hyperlipidemia on in vitro bovine embryo quality. Human Reproduction 25 768-778. (doi:10.1093/humrep/dep420)

Listenberger LL, Han X, Lewis SE, Cases S, Farese RV, Ory DS \& Schaffer JE 2003 Triglyceride accumulation protects against fatty acid induced lipotoxicity. PNAS 100 3077-3082. (doi:10.1073/pnas.0630588100)

Livak KJ \& Schmittgen TD 2001 Analysis of relative gene expression data using real-time quantitative PCR and the $2^{-\Delta \Delta C t}$ method. Methods 25 402-408. (doi:10.1006/meth.2001.1262)

Löfgren L, Ståhlman M, Forsberg GB, Saarinen S, Nilsson R \& Hansson GI 2012 The BUME method: a novel automated chloroform-free 96-well total lipid extraction method for blood plasma. Journal of Lipid Research 53 1690-1700. (doi:10.1194/jlr.D023036)

Lopaschuk GD, Ussher JR, Folmes CDL, Jaswal JS \& Stanley WC 2010 Myocardial fatty acid metabolism in health and disease. Physiological Review 90 207-258. (doi:10.1152/physrev.00015.2009)

Maillo V, Rizos D, Besenfelder U, Havlicek V, Kelly AK, Garrett M \& Lonergan P 2012 Influence of lactation on metabolic characteristics and embryo development in postpartum Holstein dairy cows. Journal of Dairy Science 95 3865-3876. (doi:10.3168/jds.2011-5270)

Maillo V, de Frutos C, O'Gaora P, Forde N, Burns GW, Spencer TE, Gutierrez-Adan A, Lonergan P \& Rizos D 2016 Spatial differences in gene expression in the bovine oviduct. Reproduction 152 37-46. (doi:10.1530/REP-16-0074)

Matoba S, O'Hara L, Carter F, Kelly AK, Fair T, Rizos D \& Lonergan P 2012 The association between metabolic parameters and oocyte quality early and late post-partum in Holstein dairy cows. Journal of Dairy Science 95 1257-1266. (doi:10.3168/jds.2011-4649)

Miessen K, Sharbati S, Einspanier R \& Schoen J 2011 Modelling the porcine oviduct epithelium: a polarized in vitro system suitable for long-term cultivation. Theriogenology 76 900-910. (doi:10.1016/j. theriogenology.2011.04.021)

Milburn JL Jr, Hirose H, Lee YH, Nagasawa Y, Ogawa A, Ohneda M, BeltrandelRio H, Newgard CB, Johnson JH \& Unger RH 1995 Pancreatic B-cells in obesity: evidence forinduction of functional, morphologic and metabolic abnormalities by increased long chain fatty acids. Journal of Biological Chemistry 270 1295-1299. (doi:10.1074/jbc.270.3.1295)

Moestrup SK \& Verroust PJ 2001 Megalin- and Cubilin-mediated endocutosis of protein-bound vitamins, lipids, and hormones in polarized epithelia. Annual Review of Nutrition 21 407-428. (doi:10.1146/ annurev.nutr.21.1.407)

Nabi IR \& Le PU 2003 Caveolae/raft-dependent endocytosis. Journal of Cell Biology 161 673-677. (doi:10.1083/jcb.200302028)

Nonogaki T, Noda Y, Goto Y, Kishi J \& Mori T 1994 Developmental blockage of mouse embryos caused by fatty acids. Journal of Assistes Reproduction and Genetics 11 482-488. (doi:10.1007/BF02215713)

Ricchi M, Odoardi MR, Carulli L, Anzivino C, Ballestri S, Pinetti A, Fantoni LI, Marra F, Bertolotti M, Banni S et al. 2009 Differential effect of oleic and palmitic acid on lipid accumulation and apoptosis in cultured hepatocytes. Journal of Gastroenterology and Hepatology 24 830-840. (doi:10.1111/j.1440-1746.2008.05733.x)

Rizos D, Carter F, Besenfelder U, Havlicek V \& Lonergan P 2010 Contribution of the female reproductive tract to low fertility in postpartum lactating dairy cows. Journal of Dairy Science 93 1022-1029. (doi:10.3168/jds.2009-2605)

Robert C 2010 Microarray analysis of gene expression during early embryo development: a cautionary overview. Reproduction 140 787-801. (doi:10.1530/REP-10-0191)

Robker RL, Akison LK, Bennett BD, Thrupp PN, Chura LR, Russell DL, Lane M \& Norman RJ 2009 Obese women exhibit differences in ovarian metabolites, hormones and gene expression compared with moderateweight women. Journal of Clinical Endocrinology and Metabolism 94 1533-1540. (doi:10.1210/jc.2008-2648)
Roche HM, Terres AM, Black IB, Gibey MJ \& Kelleher D 2001 Fatty acids and epithelial permeability: effect of conjugated linoleic acid on CaCo-2 cells. Gut 48 797-802. (doi:10.1136/gut.48.6.797)

Spitsberg VL, Matitashvili E \& Gorewit RC 1995 Association and coexpression of fatty acid binding protein and glycoprotein CD36 in the bovine mammary gland. European Journal of Biochemistry 230 872-878. (doi:10.1111/j.1432-1033.1995.tb20630.x)

Tahir MZ, George F \& Donnay I 2011 Comparison of different membrane supports for monolayer culture of bovine oviduct epithelial cells. BMC Proceedings 5 117. (doi:10.1186/1753-6561-5-S8-P117)

Tse PK, Lee YL, Chow WN, Luk JMC, Lee KF \& Yeung WSB 2008 Preimplantation embryos cooperate with oviductal cells to produce embryothrophic inactivated complement-3b. Endocrinology 149 1268-1276. (doi:10.1210/en.2007-1277)

Valckx SDM, De Pauw I, De Neubourg D, Inion I, Berth M, Fransen E, Bols PEJ \& Leroy JLMR 2012 BMI-related metabolic composition of the follicular fluid of women undergoing assisted reproductive treatment and the consequences for oocyte and embryo quality. Human Reproduction 27 3531-3539. (doi:10.1093/humrep/des350)

Valckx SDM, Van Hoeck V, Arias-Alvarez M, Maillo V, Lopez-Cardona AP, Gutierrez-Adan A, Berth M, Cortvrindt R, Bols PEJ \& Leroy JLMR 2014 Elevated non-esterified fatty acid concentrations during in vitro murine follicle growth alter follicular physiology and reduce oocyte developmental competence. Fertility and Sterility 102 1769-1776. (doi:10.1016/j.fertnstert.2014.08.018)

Valckx SDM, De Bie J, Michiels ED, Goovaerts IG, Punjabi U, RamosIbeas P, Gutierrez-Adan A, Bols PEJ \& Leroy JLMR 2015 The effect of human follicular fluid on bovine oocyte developmental competence and embryo quality. Reproductive Biomedicine Online 30 203-207. (doi:10.1016/j.rbmo.2014.10.008)

Van Hoeck V, Sturmey RG, Bermejo-Álvarez P, Rizos D, Gutierrez-Adan A, Leese HJ, Bols PEJ \& Leroy JLMR 2011 Elevated non-esterified fatty acid concentrations during bovine oocyte maturation compromise early embryo physiology. PloS ONE 6 e23183. (doi:10.1371/journal. pone.0023183)

Van Hoeck V, Leroy JLMR, Arias-Alvarez M, Rizos D, Gutierrez-Adan A, Schnorbusch K, Bols PEJ, Leese HJ \& Sturmey RG 2013 Oocyte developmental failure in response to elevated nonesterified fatty acid concentrations: mechanistic insights. Reproduction 145 33-44. (doi:10.1530/REP-12-0174)

Velazquez MA, Parrilla I, Van Soom A, Verberckmoes S, Kues W \& Niemann H 2010 Sampling techniques for oviductal and uterine luminal fluid in cattle. Theriogenology 73 758-767. (doi:10.1016/j. theriogenology.2009.07.004)

Vlaeminck B, Braeckman T \& Fievez V 2014 Rumen metabolism of 22:6n3 in vitro is dependent on its concentration and inoculum size, but less dependent on substrate carbohydrate composition. Lipids 49 517-525. (doi:10.1007/s11745-014-3905-80)

Weis L, Hoffman G, Schreiber R, Andres H, Fuchs E, Korber E \& Kolb H 1986 Fatty acid synthesis in man, a pathway of minor importance. Purification, optimal assay conditions and organ distribution of fatty acid synthase. Biological Chemistry Hoppe-Seyler 367 905-912. (doi:10.1515/bchm3.1986.367.2.905)

Wicha MS, Liotta LA \& Kidwell WR 1979 Effects of free fatty acids on the growth of normal and neoplastic rat mammary epithelial cells. Cancer Research 39 426-435.

Wolff RL, Bayard CC \& Fabien RJ 1995 Evaluation of sequential methods for the determination of butterfat fatty acid composition with emphasis on trans-18:1 acids. Application to the study of seasonal variations in French butters. Journal of American Oil Chemists' Society 72 1471-1483. (doi:10.1007/BF02577840)

Received 14 October 2016

First decision 26 November 2016

Revised manuscript received 23 February 2017

Accepted 3 March 2017 